\title{
Molecular Mechanisms of Fibroblast Growth Factor Signaling in Physiology and Pathology
}

\author{
Artur A. Belov and Moosa Mohammadi \\ Department of Biochemistry and Molecular Pharmacology, New York University School of Medicine, \\ New York, New York 10016 \\ Correspondence: Moosa.Mohammadi@nyumc.org
}

Fibroblast growth factors (FGFs) signal in a paracrine or endocrine fashion to mediate a myriad of biological activities, ranging from issuing developmental cues, maintaining tissue homeostasis, and regulating metabolic processes. FGFs carry out their diverse functions by binding and dimerizing FGF receptors (FGFRs) in a heparan sulfate (HS) cofactor- or Klotho coreceptor-assisted manner. The accumulated wealth of structural and biophysical data in the past decade has transformed our understanding of the mechanism of FGF signaling in human health and development, and has provided novel concepts in receptor tyrosine kinase (RTK) signaling. Among these contributions are the elucidation of HS-assisted receptor dimerization, delineation of the molecular determinants of ligand-receptor specificity, tyrosine kinase regulation, receptor cis-autoinhibition, and tyrosine trans-autophosphorylation. These structural studies have also revealed how disease-associated mutations highjack the physiological mechanisms of FGFR regulation to contribute to human diseases. In this paper, we will discuss the structurally and biophysically derived mechanisms of FGF signaling, and how the insights gained may guide the development of therapies for treatment of a diverse array of human diseases.

Eibroblast growth factor (FGF) signaling ful- fills essential roles in metazoan development and metabolism. A wealth of literature has documented the requirement for FGF signaling in multiple processes during embryogenesis, including implantation (Feldman et al. 1995), gastrulation (Sun et al. 1999), somitogenesis (Dubrulle and Pourquie 2004; Wahl et al. 2007; Lee et al. 2009; Naiche et al. 2011; Niwa et al. 2011), body plan formation (Martin 1998; Rodriguez Esteban et al. 1999; Tanaka et al. 2005; Mariani et al. 2008), morphogenesis (Metzger et al. 2008; Makarenkova et al. 2009), and organogenesis
(Goldfarb 1996; Kato and Sekine 1999; Sekine et al. 1999; Sun et al. 1999; Colvin et al. 2001; Serls et al. 2005; Vega-Hernandez et al. 2011). Recent clinical and biochemical data have uncovered unexpected roles for FGF signaling in metabolic processes, including phosphate/vitamin D homeostasis (Consortium 2000; Razzaque and Lanske 2007; Nakatani et al. 2009; Gattineni et al. 2011; Kir et al. 2011), cholesterol/ bile acid homeostasis (Yu et al. 2000a; Holt et al. 2003), and glucose/lipid metabolism (Fu et al. 2004; Moyers et al. 2007). Highlighting its diverse biology, deranged FGF signaling contrib-

Editors: Joseph Schlessinger and Mark A. Lemmon

Additional Perspectives on Signaling by Receptor Tyrosine Kinases available at www.cshperspectives.org

Copyright (C) 2013 Cold Spring Harbor Laboratory Press; all rights reserved; doi: 10.1101/cshperspect.a015958

Cite this article as Cold Spring Harb Perspect Biol 2013;5:a015958 
utes to many human diseases, such as congenital craniosynostosis and dwarfism syndromes (Naski et al. 1996; Wilkie et al. 2002, 2005), Kallmann syndrome (Dode et al. 2003; Pitteloud et al. 2006a), hearing loss (Tekin et al. 2007, 2008), and renal phosphate wasting disorders (Shimada et al. 2001; White et al. 2001), as well as many acquired forms of cancers (Rand et al. 2005; Pollock et al. 2007; Gartside et al. 2009; di Martino et al. 2012). Endocrine FGFs have also been implicated in the progression of acquired metabolic disorders, including chronic kidney disease (Fliser et al. 2007), obesity (Inagaki et al. 2007; Moyers et al. 2007; Reinehr et al. 2012), and insulin resistance (Fu et al. 2004; Chen et al. 2008b; Chateau et al. 2010; Huang et al. 2011), giving rise to many opportunities for drug discovery in the field of FGF biology (Beenken and Mohammadi 2012).

Based on sequence homology and phylogeny, the 18 mammalian FGFs are grouped into six subfamilies (Ornitz and Itoh 2001; Popovici et al. 2005; Itoh and Ornitz 2011). Five of these subfamilies act in a paracrine fashion, namely, the FGF1 subfamily (FGF1 and FGF2), the FGF4 subfamily (FGF4, FGF5, and FGF6), the FGF7 subfamily (FGF3, FGF7, FGF10, and FGF22), the FGF8 subfamily (FGF8, FGF17, and FGF18), and the FGF9 subfamily (FGF9, FGF16, and FGF20). In contrast, the FGF19 subfamily (FGF19, FGF21, and FGF23) signals in an endocrine manner (Beenken and Mohammadi 2012). FGFs exert their pleiotropic effects by binding and activating the FGF receptor (FGFR) subfamily of receptor tyrosine kinases that are coded by four genes (FGFR1, FGFR2, FGFR3, and FGFR4) in mammals (Johnson and Williams 1993; Mohammadi et al. 2005b). The extracellular domain of FGFRs consists of three immunoglobulin (Ig)-like domains (D1, D2, and D3), and the intracellular domain harbors the conserved tyrosine kinase domain flanked by the flexible amino-terminal juxtamembrane linker and carboxy-terminal tail (Lee et al. 1989; Dionne et al. 1991; Givol and Yayon 1992). A unique feature of FGFRs is the presence of a contiguous segment of glutamic and aspartic acids in the D1-D2 linker, termed the acid box $(\mathrm{AB})$. The two-membrane proximal D2 and D3 and the intervening D2-
D3 linker are necessary and sufficient for ligand binding/specificity (Dionne et al. 1990; Johnson et al. 1990), whereas D1 and the D1-D2 linker are implicated in receptor autoinhibition (Wang et al. 1995; Roghani and Moscatelli 2007; Kalinina et al. 2012). Alternative splicing and translational initiation further diversify both ligands and receptors. The amino-terminal regions of FGF8 and FGF17 can be differentially spliced to yield FGF8a, FGF8b, FGF8e, FGF8f (Gemel et al. 1996; Blunt et al. 1997), and FGF17a and FGF17b isoforms (Xu et al. 1999), whereas cytosine-thymine-guanine (CTG)-mediated translational initiation gives rise to multiple high molecular weight isoforms of FGF2 and FGF3 (Florkiewicz and Sommer 1989; Prats et al. 1989; Acland et al. 1990). The tissue-specific alternative splicing in D3 of FGFR1, FGFR2, and FGFR3 yields " $b$ " and " $c$ " receptor isoforms which, along with their temporal and spatial expression patterns, is the major regulator of FGF-FGFR specificity/promiscuity (Orr-Urtreger et al. 1993; Ornitz et al. 1996; Zhang et al. 2006). A large body of structural data on FGF-FGFR complexes has begun to reveal the intricate mechanisms by which different FGFs and FGFRs combine selectively to generate quantitatively and qualitatively different intracellular signals, culminating in distinct biological responses. In addition, these structural data have unveiled how pathogenic mutations hijack the normal physiological mechanisms of FGFR regulation to lead to pathogenesis. We will discuss the current state of the structural biology of the FGFFGFR system, lessons learned from studying the mechanism of action of pathogenic mutations, and how the structural data are beginning to shape and advance the translational research.

\section{STRUCTURE-FUNCTION RELATIONSHIP OF FGFs}

FGFs range in size from $\sim 150-300$ amino acids (Basilico and Moscatelli 1992; Mohammadi et al. 2005b). Crystal structures with at least one representative from each subfamily, namely FGF1 and FGF2 (Eriksson et al. 1991; Zhang et al. 1991; Zhu et al. 1991), FGF4 (Bellosta et al. 2001), FGF7 (Ye et al. 2001), FGF8b (Olsen 
et al. 2006), FGF9 (Plotnikov et al. 2001), FGF10 (Yeh et al. 2003), FGF19 (Harmer et al. 2004; Goetz et al. 2007), FGF20 (Kalinina et al. 2009), and FGF23 (Goetz et al. 2007) have been solved. In addition, crystal structures of FGF1, FGF2, FGF8b, and FGF10 in complex with their cognate receptor(s) have been solved, providing valuable insights into the structure-function relationships of the FGF family (Fig. 3). These structures show that the FGF core homology domain (composed of $\sim 125$ amino acids) adopts a conserved $\beta$-trefoil fold consisting of 12 antiparallel $\beta$ strands $(\beta 1-\beta 12)$ in paracrine FGFs (Mohammadi et al. 2005b). Endocrine FGFs lack the $\beta 11$ strand, and hence have an atypical trefoil fold (Goetz et al. 2007; Beenken and Mohammadi 2011). The FGF trefoil core is flanked by amino- and carboxy-terminal regions that are highly variable in length and sequence among FGFs. These variable amino and carboxyl termini contribute key components in the regulation of distinct biological functions of different FGFs.

Paracrine FGFs exhibit moderate to high affinity for heparan sulfate (HS), a mandatory cofactor in paracrine FGF signaling (Rapraeger et al. 1991; Yayon et al. 1991; Ornitz and Leder 1992). HS is a heterogeneously sulfated glycosaminoglycan that is covalently linked to select serine residues in proteoglycans, such as membrane-anchored syndecans and glypicans and extracellular matrix (ECM) perlecans (Hacker et al. 2005; Iozzo et al. 2009). HS is a polymer of repeating disaccharide units consisting of glucuronic acid and amino acteylglucosamine linked through $\alpha-1,4$-glycosidic bonds. HS is heterogeneously sulfated on the $2-\mathrm{O}$ position of glucuronic and amino acids and the 6-O position of amino acteylglucosamine (Esko and Lindahl 2001). Attributed to their high affinity for HS, paracrine FGFs can diffuse only a short distance away from their source of secretion, thus acting locally (Asada et al. 2009; Xu et al. 2012). Unique among paracrine FGFs, the FGF9 subfamily undergoes reversible dimerization, whereby the dimer has higher affinity for HS. This provides an additional mechanism for acutely regulating the diffusion radius of the FGF9 subfamily of ligands, further reducing their signaling dimensionality (Plotnikov et al. 2001; Harada et al. 2009; Kalinina et al. 2009). The HS binding site of FGFs is composed of the $\beta 1-\beta 2$ loop and the extended $\beta 10-\beta 12$ region, which provide solvent-exposed basic amino acids and backbone atoms for HS binding (Fig. 1B). Because of the primary sequence variation of the HS binding site, each ligand has discrete affinity for HS, resulting in the formation of FGF-specific morphogenetic gradients that contribute to the distinct biology of FGF (Makarenkova et al. 2009). Despite primary sequence variations, however, the HS binding sites of paracrine FGFs adopt a common topology ( $\mathrm{Fa}$ ham et al. 1998; Goetz et al. 2007). This is mainly because of the presence of the paracrineconserved GXXXXGXXS/T motif (Goetz et al. 2007), referred to as the glycine box (Luo et al. 1998). The backbone atoms of these two glycines engage in conserved hydrogen bonds with underlying $\beta$ strands to facilitate the formation of the $\beta 11$ strand (Goetz et al. 2007) (Fig. 1B).

The topology of the HS binding region of the endocrine FGFs differs drastically from that of paracrine FGFs because of the lack of the paracrine-conserved glycine box and the truncated $\beta 10-\beta 12$ region (Goetz et al. 2007) (Fig. 1B). Importantly, the altered topologies of HS binding sites of the endocrine FGFs disallow the interaction of HS with the backbone atoms of the HS binding region. This manifests itself in major reductions in $\mathrm{HS}$ affinity of the endocrine FGFs (Yu et al. 2005; Goetz et al. 2007), which allows these ligands to permeate freely through the HS-rich ECM and enter blood circulation (Fig. 1A,C).

\section{STRUCTURAL FEATURES OF FGFRs}

Currently, there is no crystal structure of either the intact ectodomain or the D2-D3 ligandbinding region of FGFR in the absence of the ligand. Nuclear magnetic resonance (NMR) solution studies of the D2-D3 region show that D3 is an intrinsically flexible domain (Kalinina et al. 2012). However, in the $\mathrm{X}$-ray structures of ligand-bound D2-D3, D3 adopts a stable Ig-like fold (Plotnikov et al. 1999). To date, there are crystal structures of eight different 
A.A. Belov and M. Mohammadi

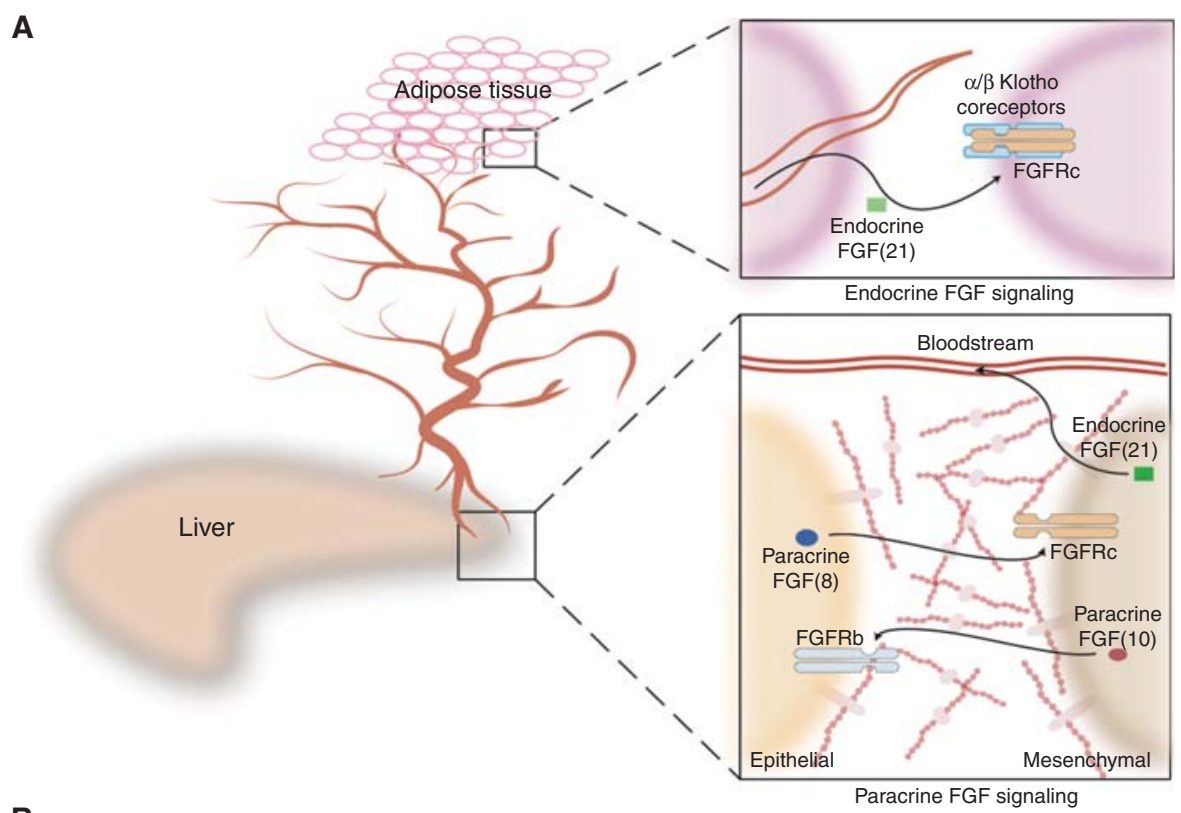

B

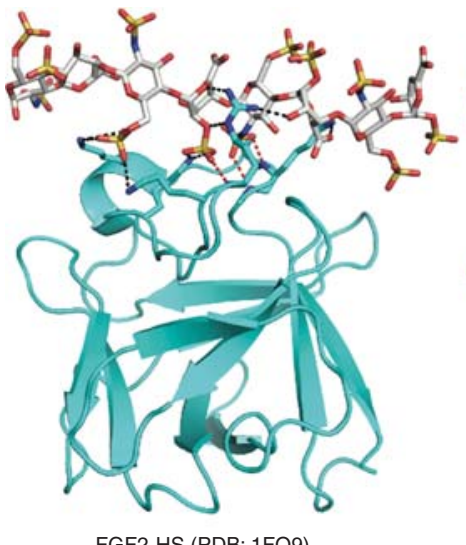

FGF2-HS (PDB: 1FQ9)

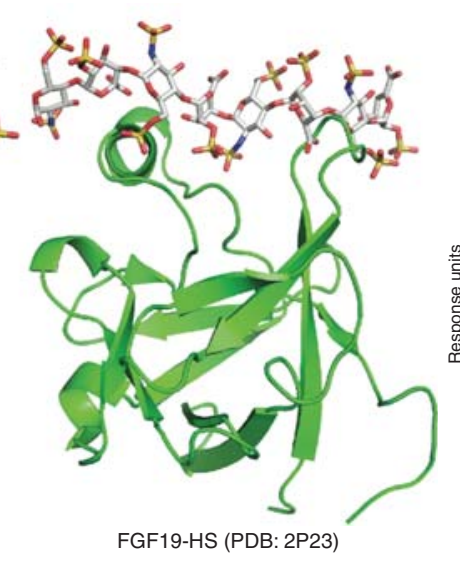

C

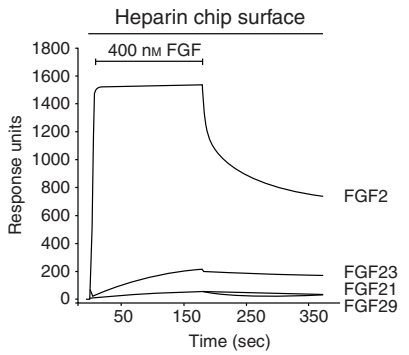

Figure 1. FGF signaling in the liver and adipose tissue. (A) The paracrine FGF signaling loop in the liver. FGFs are expressed in both the epithelial or mesenchymal tissue, and signal in a paracrine fashion through their cognate receptors, which are expressed in the opposite tissues. Shown are two examples of paracrine ligands, FGF8 and FGF10, which signal exclusively in an epithelial-to-mesenchyme and mesenchyme-to-epithelial manner, respectively. (B) Comparison of the crystal structures of FGF2 (PDB: 1FQ9) and FGF19 (PDB: 2P23) provides the structural basis for the low affinity of endocrine ligands for HS. $(C)$ Comparison of the binding interactions of FGF2, FGF19, FGF21, and FGF23 with HS using surface-plasmon resonance spectroscopy. The low affinity of FGF19 family members (such as FGF21) allows them to permeate freely through the HS-dense intercellular space and enter into the blood. This enables them to act as hormones in target tissues in which $\alpha / \beta$ Klotho coreceptors are expressed (top panel in part $A$ ).

FGF-FGFR complexes that feature unique ligand-receptor combinations, including FGF1 with FGFR1c (Plotnikov et al. 2000; Beenken et al. 2012), FGFR2c (Stauber et al. 2000), FGFR3c (Olsen et al. 2004), FGFR2b (Beenken et al. 2012), FGF2 with FGFR1c (Plotnikov et al. 1999; Schlessinger et al. 2000), FGFR2c (Plotnikov et al. 2000), FGF8b with FGFR2c (Olsen et al. 2006), and FGF10 with FGFR2b (Yeh et al. 2003). In all these structures, the receptor 
adopts an extended conformation displaying significant differences in the relative orientation of D2 and D3 to one another, suggesting that the overall receptor orientation is dictated by ligand binding (Fig. 3). This is harmonious with the fact that there are no intramolecular contacts between D2 and D3 that would constrain the relative disposition of the two domains in the absence of the ligand.

As anticipated based on sequence homology (Bateman and Chothia 1995), D1 and D2 adopt Ig folds that belong to the I set of the Ig superfamily (Plotnikov et al. 1999; Hung et al. 2005; Kiselyov et al. 2006) (Fig. 2A). In contrast, D3 has an unusual Ig-fold in that the region between the $\beta C^{\prime}$ and $\beta E$ strands (referred to as the $\beta C^{\prime}-$ $\beta E$ loop) adopts a different conformation in different complexes, suggesting that it is highly mobile. In all but the FGF8b-FGFR2c structure, D3 lacks the analogous $\beta \mathrm{D}$ strand of the Ig-like domains D1 and D2. Notably, alternative splicing of D3 occurs at the junction between the $\beta C^{\prime}$ strand and the $\beta C^{\prime}-\beta E$ loop, diversifying the primary sequence of the loop (Johnson et al. 1991; Yeh et al. 2003) (Fig. 2A). As we will discuss later, this, together with the inherent flexibility of the loop, plays a major role in determining ligand-binding specificity/promiscuity. The HS binding site of the receptor resides in D2 and is comprised of several surface-exposed residues
A

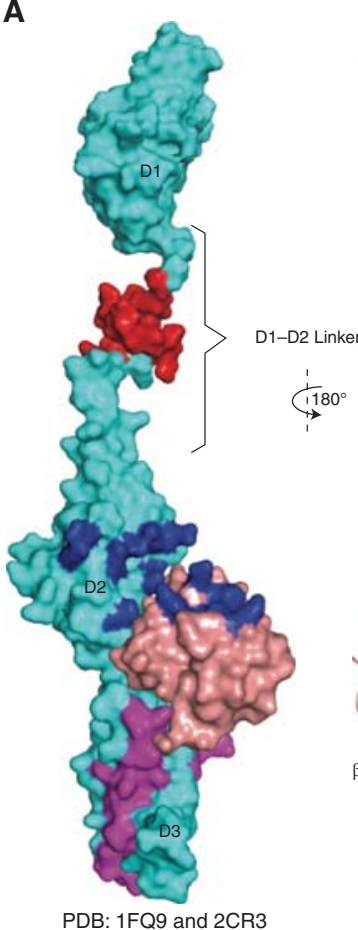

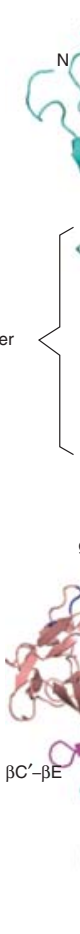

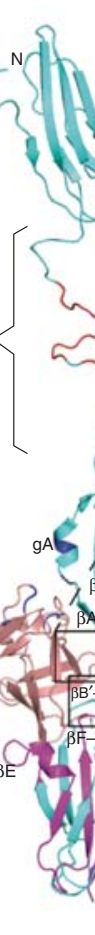

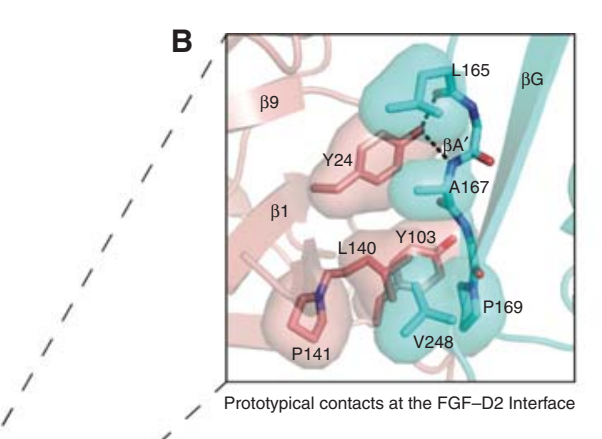

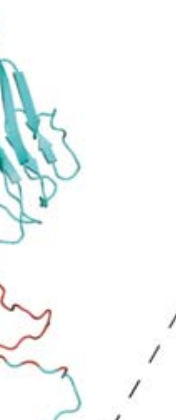

C
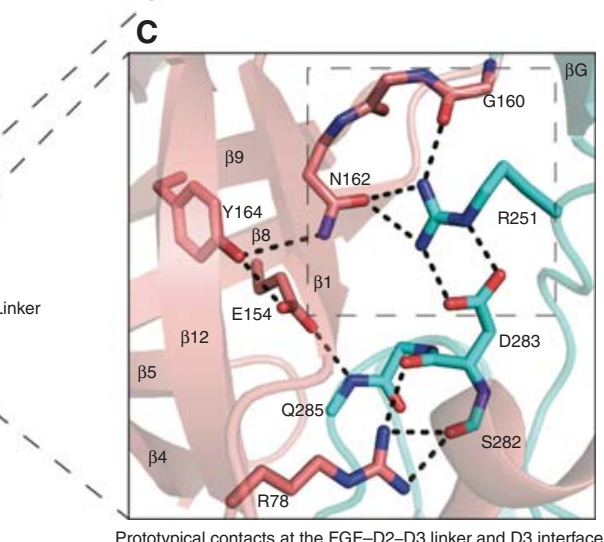

Figure 2. Structural features of a prototypical FGF receptor and FGF-conserved FGF-FGFR contacts. (A) The Xray structure of FGF2-FGFR1c (PDB: 1FQ9) and an NMR structure of D1 (PDB: 2CR3) were linked arbitrarily with a modeled D1-D2 linker to construct a model of a full-length FGF receptor. The acid box is red and the HS binding region in the FGF2-FGFR1c complex is blue. FGFR1c and FGF2 are cyan and salmon, respectively. The alternatively spliced portion of D3 is magenta. (B) Prototypical contacts (PDB: 1FQ9) between the ligand and receptor D2 are illustrated. Dashed lines denote hydrogen bonds. Hydrophobic contacts are indicated using transparent surfaces. Oxygen and nitrogen atoms are red and blue, respectively, hereafter. $(C)$ The conserved hydrogen bonds at the interface between the D2-D3 linker and D3 of the FGFR and FGF ligand as observed in the FGF10-FGFR2b structure (PDB: 1NUN). The dashed box within panel $C$ highlights the hydrogen bonds between the D2-D3 linker of FGFR and FGF. 
emanating from the $\beta B, \beta E, \beta D$ strands, the $g A$ helix, and the loop between the $\beta A$ and $\beta A^{\prime}$ strands of D2 (Schlessinger et al. 2000). Unlike the FGF-HS interaction, only the side chains of D2 participate in HS coordination, which explains the significantly lower affinity of FGFRs for HS compared to that of FGFs (Powell et al. 2002; Ibrahimi et al. 2004c; Asada et al. 2009; Trueb 2011).

The bottom edge of D2, the D2-D3 linker, and the top portion of D3 compose the ligandbinding pocket (Plotnikov et al. 1999) (Fig 2A). The FGF straddles D3 via the bottom end of the trefoil (the top end being the HS binding site). The $\beta B^{\prime}-\beta C$ and $\beta F-\beta G$ loops in $D 3$ are engulfed in a depression formed between the $\beta 1$, $\beta 2, \beta 4, \beta 5, \beta 8$, and $\beta 9$ strands and the intervening loops, whereas the D2-D3 linker cooperates with D3 to further fix the ligand in its observed position (Fig. 2C). The $\beta \mathrm{A}^{\prime}$ and $\beta \mathrm{F}$ strands at the bottom edge of $\mathrm{D} 2$ sharply engage the $\beta 1$ through $\beta 2$ strands, the $\beta 3-\beta 4$ loop, and $\beta 9$ and $\beta 12$ of the ligand (Plotnikov et al. 2000) (Fig. 2A).

\section{THE FGF-FGFR INTERFACE}

\section{Conserved Ligand-Receptor Contacts}

Each subdomain makes several highly conserved contacts with the ligand, unambiguously demonstrating that the D2-D3 fragment is the minimal binding region of FGFs (Stauber et al. 2000; Olsen et al. 2004; Mohammadi et al. 2005b). At the FGF-D2 interface, two conserved tyrosine residues, one from the $\beta 1$ strand and another from the $\beta 8-\beta 9$ loop, along with highly conserved proline in the $\beta 12$ strand of the ligand engage in hydrophobic and hydrogen-bonding interactions with conserved residues on the $\beta \mathrm{A}^{\prime}$ and $\beta G$ strands in D2 (Fig. $2 B$ ). The interface between FGF and the D2-D3 linker is by far the most conserved residue. Here, an invariant arginine from the D2-D3 linker region makes three hydrogen bonds with a side chain of a residue in $\beta 9$ and a backbone of the $\beta 8-\beta 9$ loop in the ligand (Fig. 2C). The $\beta 9$ residue is an asparagine in all FGFs, with the exception of the FGF8 subfamily, which has a threonine instead. Notably the D2-D3 linker arginine is also engaged in intramolecular hydrogen bonding with a conserved aspartic acid in the $\beta \mathrm{B}^{\prime}-\beta C$ loop of $\mathrm{D} 3$. This primes the arginine for FGF recognition, thus minimizing the entropic penalty associated with ligand binding. The focal role of these hydrogen bonds in providing general FGF-FGFR affinity is evidenced by the fact that fibroblast homologous factors (FHFs) contain a valine in the equivalent position of $\beta 9$ asparagine, which hinders them from binding/activating FGFRs (Goldfarb 1996; Olsen et al. 2003; Goetz et al. 2009; Wang et al. 2012). Mutation of the D2-D3 linker arginine to glutamine leads to a loss of function in the Kallmann syndrome (Dode et al. 2003; Pitteloud et al. 2006a,b), further highlighting the importance of these conserved hydrogen bonds in FGF-FGFR binding. The FGFD3 interface harbors two highly conserved contacts. Here the backbone atoms of the $\beta B^{\prime}-\beta C$ loop are engaged in three strong hydrogen bonds with an arginine from $\beta 1$ and glutamic acid from $\beta 8$ of the ligand (Fig. $2 \mathrm{C}$ ). Together, the aforementioned contacts provide general FGF-FGFR binding affinity, whereas specificity is primarily decided by divergent contacts at the FGF-D3.

\section{ALTERNATIVE SPLICING IN D3 IS A MAIN MECHANISM IN REGULATION OF FGF- FGFR SPECIFICITY}

In FGFR1-3, two alternative exons ("b" and "c") code for the second half of D3 (Johnson et al. 1991; Miki et al. 1992; Yayon et al. 1992) that are spliced in tissue-specific fashion (OrrUrtreger et al. 1993; Wuechner et al. 1996; Beer et al. 2000). Generally, the b-splice variants are expressed in the epithelial tissue, whereas the csplice isoforms are expressed in the mesenchymal tissue (Orr-Urtreger et al. 1993; McEwen and Ornitz 1997). Paracrine FGFs also show tissue-specific expression patterns with ligands for FGFRb isoforms being expressed in mesenchyme, and ligands for FGFRc isoforms expressed in epithelium (Finch et al. 1989). This results in an epithelial-mesenchymal FGF signaling loop that is crucial for tissue homeostasis and organogenesis (McIntosh et al. 2000; Itoh and Ornitz 2011), as evidenced by the fact that 
derangements of this signaling loop contribute to human skeletal disorders and cancer (Ibrahimi et al. 2005; Beenken and Mohammadi $2009,2011)$. The tissue-specific alternative splicing in $\mathrm{D} 3$ is the chief mechanism in the regulation of FGF-FGFR binding specificity (Yayon et al. 1992; Ornitz et al. 1996; Zhang et al. 2006). Crystallographic studies of eight different FGF-FGFR complexes have revealed that this alternative splicing controls FGF-FGFR binding specificity/promiscuity by altering the composition of FGF binding sites in D3, including the $\beta C^{\prime}-\beta E$ and $\beta F-\beta G$ loops. Moreover, the $\beta C^{\prime}-\beta E$ loop is inherently flexible, and is capable of adapting uniquely to each ligand. The regions of FGFs that engage the alternatively spliced half of D3, in particular, the amino-terminal region of ligands, is divergent in the primary sequence. These structural data flag the FGF-D3 interface as the key mediator of FGFFGFR binding specificity/promiscuity. The current structural data on FGF-FGFR complexes have disclosed two distinct modes by which contacts at the FGF-D3 interface mediate FGFFGFR binding specificity.

\section{GENERAL MODE OF FGF-FGFR SPECIFICITY}

The hallmark of the general mode, observed in the FGF1-, FGF2-, and FGF10-receptor complexes, is a cleft in $\mathrm{D} 3$ that forms between $\beta \mathrm{B}^{\prime}-$ $\beta C$ and the alternatively spliced $\beta C^{\prime}-\beta E$ on ligand binding. This cleft is induced by hydrophobic contacts between residues from the $\beta 7$ and $\beta 8$ loops and the $\beta 5$ strand in the FGF core, and a hydrophobic residue at the apex of the alternatively spliced $\beta C^{\prime}-\beta E$ of the receptor (Fig. 3A-C). Residues from the $\beta 4, \beta 5$ strands and the intervening loop as well as the aminoterminal tail of the ligand engage the $\beta C^{\prime}-\beta E$ loop, further stabilizing the cleft. The $\beta F-\beta G$ loop, which is also alternatively spliced, engages residues from the $\beta 4-\beta 5$ loop and the $\beta 8$ strand.

\section{FGF7 Subfamily}

FGF7 subfamily members are secreted by the mesenchyme and act exclusively on the FGFR2b resident in the epithelial tissue to constitute the mesenchymal-to-epithelial arm of the signaling loop (Mason et al. 1994). The FGF10-FGFR2b structure (Yeh et al. 2003) shows that F146, Y131, and A122 in FGF10 form a hydrophobic surface that tethers Ile-317 from the alternatively spliced loop promoting formation of the D3 cleft (Fig 3B). According to the structure, the FGF7 subfamily's preference for FGFR2b can be traced to the highly specific hydrogen bonds between Asp-76, a unique amino-terminal residue in the FGF7 subfamily, and Ser-315 from the alternatively spliced $\beta C^{\prime}-\beta E$ loop in the D3 cleft. A $\pi$-cation interaction between Y345 in the $\beta F-\beta G$ (a residue unique to b-splice isoforms of receptors) and R155 in the $\beta 8$ strand of FGF10 further reinforces the specificity (Fig. $3 \mathrm{~A}, \mathrm{~B})$. Interestingly, the substitution of the conserved tyrosine in the $\beta 1$ strand for phenylalanine in the FGF7 subfamily acts in concert with the above-mentioned specific FGF-D 3 contacts to further narrow the specificity of the FGF7 subfamily for FGFR2b. This $\mathrm{Y} \rightarrow \mathrm{F}$ substitution disables this subfamily form hydrogen bonding with D2 (Fig. 2B), thus minimizing the contribution of D2 in providing ligand-binding affinity. By primarily relying on the alternatively spliced loops of D3 of the receptor to attain specificity and affinity, the FGF7 subfamily is solely able to bind and activate FGFR2b. In the absence of these hydrogen bonds that impose constrains on the orientation of D3, D2 is observed to rotate about the D2-D3 linker, resulting in a distinct orientation of the HS binding site in D2, relative to the ligand. This structural change has been postulated to play a role in determining the HS selectivity of the FGF7 subfamily FGFR2b complexes (Mohammadi et al. 2005a).

\section{FGF1 Subfamily}

Unlike the FGF7 subfamily, whose members share a common receptor specificity profile, the members of the FGF1 subfamily, namely FGF1 and FGF2, have a distinct receptor binding specificity/promiscuity profile (Ibrahimi et al. 2004a,b). Both FGF1 and FGF2 are promiscuous and can bind more than one FGFR isoform. 
A.A. Belov and M. Mohammadi

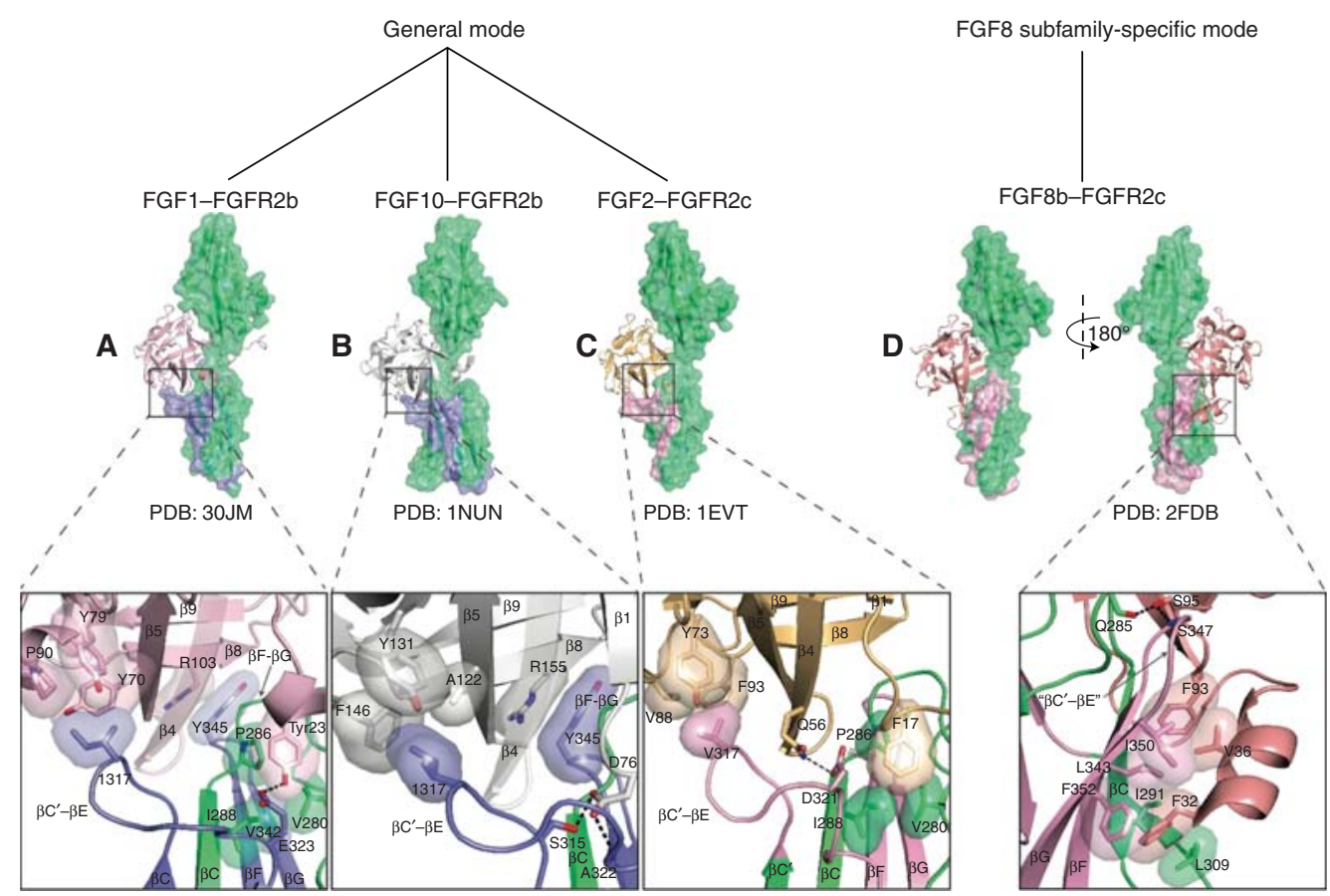

Figure 3. General and FGF8-specific modes of FGF-FGFR binding. FGF1 and FGF10 in complex with FGFR2b are illustrated with the alternatively spliced regions of D3 shown in slate. FGF2 and FGF8b in complex with FGFR2c are also illustrated, with the alternatively spliced regions of D3 in pink. FGF1, FGF10, FGF2, and FGF8b are light pink, gray, wheat, and salmon, respectively. The constant regions of FGFRs are lime green. Each subpanel illustrates the specific contacts the ligands make with $\mathrm{D} 3$. In the subpanels $A$ and $B$, the $\beta 4$ strands from FGF1 and FGF10 are made transparent to allow for the visualization of the $\pi$-cation interactions at the $\beta F-$ $\beta \mathrm{G}$ loop outside of the D3 cleft.

FGF2 binds equally well to the "c" isoforms of FGFR1 and FGFR2 but has negligible binding to the "b" isoforms (Ornitz et al. 1996). In contrast, FGF1 overrides the specificity barrier set by alternative splicing and interacts indiscriminately with all seven FGFRs (Zhang et al. 2006).

Crystal structures of FGF2 with both of its cognate receptors have been solved (Plotnikov et al. 1999, 2000), revealing the molecular basis for the FGFR binding specificity/promiscuity of FGF2. Reminiscent of the FGF10-FGFR2b structure, a valine/isoleucine at the apex of the $\beta C^{\prime}-\beta E$ loop makes hydrophobic contacts with $\mathrm{Y} 73$ (from the $\beta 6$ strand) and V88 and F93 (from the $\beta 7-\beta 8$ loop), resulting in the formation of the D3 cleft (Fig. 3C). The specificity/ promiscuity of FGF2 can be traced mostly to specific hydrogen bonds between Q56 from the $\beta 4$ strand of FGF2 and D321 in the D3 cleft.
F17 from the amino terminus is immersed in a hydrophobic pocket created by I288, P286, and V280 in the D3 cleft, while also engaging in hydrogen-aromatic interactions with D321 (Fig. $3 C$ ). The $\beta C^{\prime}-\beta E$ loop of "b-" splice isoforms would not be able to endorse these specific contacts.

The crystal structure of FGF1 in complex with four of its cognate FGFRs, namely, FGFR1c (Plotnikov et al. 2000; Beenken et al. 2012), FGFR2c (Stauber et al. 2000), FGFR3c (Olsen et al. 2004), and FGFR2b (Beenken et al. 2012), have been solved. Analysis of these four FGF1FGFR structures show that the promiscuity of FGF1 can be traced to the unusual ability of FGF1 to adapt to the alternatively spliced $\beta C^{\prime}-\beta E$ loop on the receptor. The versatility in the interactions of FGF1 with the $\beta C^{\prime}-\beta E$ loop manifests itself in the observed divergent 
conformation of the $\beta C^{\prime}-\beta E$ loop in the four FGF1-FGFR structures. The FGF1-FGFR1c, FGF1-FGFR2c, and FGF1-FGFR2b complexes all feature the characteristic D3 cleft, whereas the FGF1 -FGFR3c structure lacks it. Three amino-terminal residues of FGF1, namely, F16, N22, and Y23 FGF1 make variable interactions with D3, depending on which receptor they interact with (Beenken et al. 2012). Replacing the corresponding three amino-terminal residues in FGF2 with that of FGF1 bestows on FGF2 the ability to bind to the FGFR2b isoform, thus verifying the structural data. As a corollary to FGF10 specificity, subtle changes at the FGF1-D2 contacts augment the promiscuity of FGF1. Notably, FGF1 has an L135 instead of an M142 in FGF2 at the FGF-D2 interface, which enables FGF1 to engage in stronger hydrophobic contacts with D2, thereby gaining more affinity through D2 contacts. This enhances the promiscuity of FGF1 as it reduces the dependency of FGF1 on D3 for receptor binding.

Structural and biochemical studies of pathogenic mutations affecting the extracellular domain of FGFRs strongly support the regulatory mechanisms of FGF-FGFR binding specificity/ promiscuity deduced from FGF-FGFR crystal structures (Wilkie 2005). For example, the S252W and P253R mutations in the D2-D3 linker region of FGFR2, responsible for the Apert syndrome (Wilkie et al. 1995), introduce additional conserved contacts with FGFs that result in a generalized increase in affinity of the receptor for all FGFs, thus minimizing the reliance of FGF on specific contacts with D3 for receptor binding (Anderson et al. 1998; Ibrahimi et al. 2001; Yu and Ornitz 2001; Glaser et al. 2003; Yoon et al. 2009). This enables the mesenchymally expressed diseased FGFR2c to illegitimately bind and become activated in an autocrine fashion by mesenchymmal FGF10, thereby short-circuiting the epithelial-to-mesenchyme signaling polarity (Yu et al. 2000b). Likewise, structural studies of the D321A mutation, which maps onto the $\beta C^{\prime}-\beta E$ loop of FGFR2c, show that this mutation removes the electrostatic repulsion and steric conflict that prohibits binding of FGFR2c to FGF10, thereby enabling the illegitimate activation of the "diseased" receptor by FGF10 in the mesenchyme (Ibrahimi et al. 2004a).

\section{FGF8 SUBFAMILY-SPECIFIC MODE OF FGF-FGFR SPECIFICITY}

FGF8 subfamily members are expressed in the epithelial tissue and activate the c-splice isoforms of FGFRs that reside in the underlying mesenchyme to mediate the epithelial-to-mesenchymal arm of the signaling loop (Blunt et al. 1997). Members of the FGF8 subfamily share an overlapping receptor binding specificity/ promiscuity profile and bind redundantly to FGFR1c-3c and FGFR4 (Ornitz et al. 1996). The FGF8 subfamily uses a different mode to attain FGFR binding specificity that can be traced to unique prestructured amino termini of this subfamily. In contrast to FGF1, FGF2, and FGF10, which have flexible amino termini, the amino terminus of the FGF8 subfamily adopts a rigid conformation that enables it to wrap around D3 and engage the opposite face of D3 (Olsen et al. 2006) (Fig. 3D). Structural analysis shows that in FGF1, FGF2, and FGF10, the first occurrence of a glycine or proline aborts the $\beta 1$ strand amino terminally, while also causing the amino terminus to turn away from D3. In the FGF8 subfamily, however, the absence of an amino-terminal proline/glycine allows the $\beta 1$ strand to continue stranding with $\beta 4$, which places the amino terminus in an opposite orientation compared to FGF1, FGF2, and FGF10 (Olsen et al. 2006). FGF8b residues F32-S40 form a g helix, which is linked to the $\beta 1$ strand via an extended loop. The conformation of this loop is stabilized by intramolecular contacts with the FGF8 core. F32, V36 from the gN helix, along with F92 from the $\beta 4-\beta 5$ loop, engage an extended hydrophobic groove formed by I291 ( $\beta$ C), L309 $\left(\beta C^{\prime}\right)$, L343 $(\beta F)$, I350 $(\beta G)$, and F352 $(\beta G)$ at the bottom sheet of D3 (Fig. 3D). The $\beta \mathrm{F}$ and $\beta G$ strands reside in the alternatively spliced half of D3, and the replacement of L343 and $\mathrm{I} 350$ by polar residues in $\mathrm{b}$ isoforms of FGFR1-3 and FGFR4 explain the subfamily's specificity for FGFRc isoforms and FGFR4 (Olsen et al. 2006). Additional specificity is mediated by the FGF8-specific serine insertion in the 
$\beta 4-\beta 5$ loop, which forms a unique network of hydrogen bonds with the backbone atoms of the alternatively spliced $\beta \mathrm{B}^{\prime}-\beta C$ and $\beta \mathrm{F}-\beta \mathrm{G}$ loops.

The $\beta C^{\prime}-\beta E$ loop conformation is totally rearranged to make room for the unique FGF8 amino terminus. In fact, a section of this loop forms the canonical Ig-folded $\beta D$ strand that is connected to $\beta E$ through a short loop. All the loops connecting the strands of the top sheet localize on one side, and, as a result, the FGF8b-FGFR2c structure lacks the D3 cleft. The unique mode of FGF8b-FGFR2c binding induces a unique $\mathrm{D} 3$ rotation that pivots about the D2-D3 linker. Modeling studies show that the membrane insertion points of receptor monomers in the FGF8b-FGFR2c dimer would be closer by $\sim 15 \AA$ vis-à-vis the FGF2-FGFR2c dimer. These topological differences have been postulated to contribute to the distinct signaling capacity by different FGFs (Olsen et al. 2006). The L341S loss-of-function mutation in FGFR1, which is responsible for the Kallmann syndrome, maps to the D3 groove that the FGF8 subfamily engages (Dode et al. 2003; Pitteloud et al. 2006a; Falardeau et al. 2008). The substitution of leucine for the polar serine in this hydrophobic groove severely impairs the FGF8b binding, thus implicating the FGF8 subfamily in the etiology of the Kallmann syndrome. Indeed, subsequent genetic screening of a cohort of patients led to the identification of loss-offunction mutations in FGF8 and FGF17 (Falardeau et al. 2008; Trarbach et al. 2010; McCabe et al. 2011).

In summary, contacts between FGF and alternatively spliced regions in D3 dictate FGFFGFR specificity and promiscuity, whereas contacts between FGF and D2 and the D2-D3 linker serve primarily to provide basal ligand-binding affinity. Importantly, differences in the contacts between FGF and D2 and/or D2-D3 contacts can enhance specificity/promiscuity of FGFs by modifying the basal FGF-FGFR affinity. The fidelity of FGF-FGFR binding specificity/ promiscuity combined with ligand-dependent differences in receptor orientation would allow for the precise regulation of FGF-induced signaling.

\section{HS-ASSISTED PARACRINE FGF-FGFR DIMERIZATION}

HS is a mandatory cofactor in paracrine FGF signaling (Imamura and Mitsui 1987; Rapraeger et al. 1991; Yayon et al. 1991; Olwin and Rapraeger 1992; Ornitz et al. 1992), as documented by the fact that mice and flies with defects in components of FGF signaling or HS biosynthetic enzymes share overlapping phenotypes (Lin et al. 1999; Inatani et al. 2003). Structural data have shown that HS promotes the formation of a symmetric 2:2:2 dimer between FGF, FGFR, and HS, which is required for signal transmission across the plasma membrane (Schlessinger et al. 2000). In the dimeric complex, FGFs engage D2, D3, and the D2-D3 linker of their primary receptor (as discussed in depth above). In addition, residues from the $\beta 8-\beta 9$ and $\beta 11-\beta 12$ loops of FGFs interact with the $\beta C^{\prime}-\beta D$ and $\beta E-\beta F$ loops in D2 of the neighboring (secondary) receptor (Fig. $4 \mathrm{~A}$ ). Notably, the primary sequence of the $\beta 11-\beta 12$ loop shows considerable variation among FGFs, indicating that additional FGF-FGFR signaling specificity may be achieved on receptor dimerization. The dimer interface is further fortified by the direct interactions between FGFRs mediated via the bottom end of their D2 domains (Fig. 2A, B). A 2:2:1 FGF-FGFR-HS asymmetric model has also been proposed (Pellegrini et al. 2000); however, analysis of the mechanism of action of pathogenic mutations has lent unbiased support for the symmetric mode of dimerization (Mohammadi et al. 2005a). For example, the A172F gain-of-function mutation that is implicated in the Pfeifer syndrome maps to the D2-D2 receptor interface that has been shown to cause gain of function by facilitating ligand-dependent FGFR dimerization (Ibrahimi et al. 2005).

The HS binding sites of the ligands and receptors are adjacent to one other, forming a continuous basic canyon on the membrane distal end of the dimer. The HS binding residues of FGFs and FGFRs act in concert to recruit two HS molecules in a symmetric fashion (Fig. 4A). Each HS oligosaccharide makes a total of 30 hydrogen bonds with a single FGF and both 


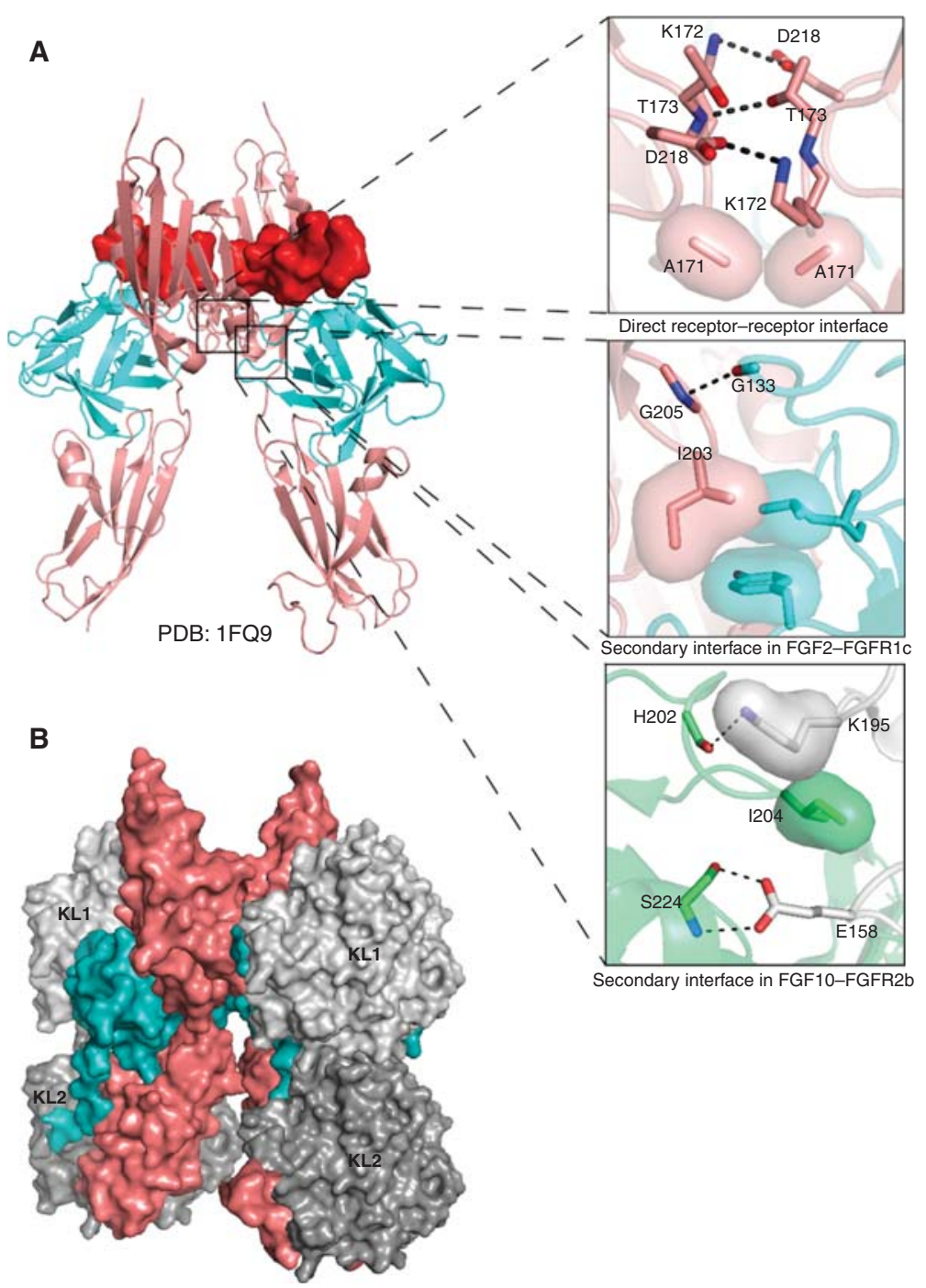

Figure 4. HS/Klotho-assisted FGFR dimerization. (A) FGF2-FGFR1c-HS ternary complex (PDB:1FQ9). FGF2 (cyan) and FGFR1c (salmon) are shown in ribbons, while HS is depicted in the surface representation (red). The top panel illustrates the direct receptor-receptor contacts. In the middle and bottom panels, secondary receptor-ligand contacts are shown for the 2:2 FGF2-FGFR1c and 2:2 FGF10-FGFR2b dimers, respectively. (B) A working model for the endocrine FGF-FGFR-Klotho signaling dimer constructed by the superimposition of the FGF23 structure (PDB: 2P23) onto FGF2 in the FGF2-FGFR1c-HS ternary complex (PDB:1FQ9). The two Klotho (KL) domains, shown in two shades of gray, were modeled using the crystal structure of myrosinase (PDB: 1E6S). The carboxy tail of FGF23 is also modeled to show that it engages a composite site created at the FGFR-Klotho interface.

receptor D2 domains (Schlessinger et al. 2000). Primary sequence differences at the HS binding sites of FGFs and FGFRs are proposed to lead to the formation of distinctly charged canyons destined to bind tissue-specific HS molecules
(Mohammadi et al. 2005a; Zhang et al. 2009). Notably, the primary and secondary FGF-FGFR binding sites on D2, the direct FGFR-FGFR binding site, and the HS binding site are adjacent to each other, indicating that HS-mediated 
A.A. Belov and M. Mohammadi

dimerization is a cooperative process (Fig. 4A, middle and bottom panels). By engaging ligand and receptors in the dimer, HS promotes the kinetics and thermodynamics of FGF-FGFR binding and dimerization, allowing for the transmission of a sustained and robust intracellular signal as opposed to the transient downstream signaling that is observed in HS-deficient cells (Yayon et al. 1991; Nugent and Edelman 1992; Ornitz et al. 1992; Mathieu et al. 1995; Delehedde et al. 2000).

\section{KLOTHO CORECEPTOR-DEPENDENT ENDOCRINE FGF SIGNALING}

In addition to exhibiting a negligible HS binding affinity (Fig. 1C), the endocrine FGFs also have poor affinity for their cognate FGFRs (Goetz et al. 2012b). Modeling studies show key residues at their predicted receptor binding site of endocrine FGFs are substituted for residues that are suboptimal for receptor binding (Goetz et al. 2007) (Fig. 1B). For example, substitution of the conserved arginine in the $\beta 1$ strand and glutamic acid in the $\beta 8$ strand with glycine and histidine, respectively, in FGF23 should cause a major reduction in receptor binding affinity of this ligand. As discussed earlier, each of these two residues make conserved hydrogen bonds with D3 to provide general receptor binding affinity (Fig. 2B,C). The poor HS binding affinity, along with negligible FGFR binding affinity renders HS ineffective in promoting endocrine FGFFGFR binding and dimerization (Goetz et al. 2007; Beenken and Mohammadi 2012). Instead, these ligands must rely on $\alpha / \beta$ Klotho coreceptors to signal (Urakawa et al. 2006; Kurosu et al. 2007; Ogawa et al. 2007; Kharitonenkov et al. 2008; Suzuki et al. 2008; Kuro-o 2012). Klotho coreceptors are single-pass transmembrane proteins whose ectodomain consists of tandem KL domains, which are homologous to $\beta$-glucosidases (Kuro-o et al. 1997; Ito et al. 2000). The Klotho coreceptors have been shown to associate constitutively with the c-splice isoforms of FGFR1 -3 and FGFR4 to promote binding and dimerization of endocrine FGF-FGFR complexes (Kurosu et al. 2006, 2007; Goetz et al. 2012a). The Klotho dependency confines the target tissue specificity of endocrine FGFs to those that express $\alpha$ Klotho and $\beta$ Klotho (Wu et al. 2007; Kurosu and Kuro-o 2008). Signaling specificity is further reinforced by the inherent specificity of FGF19 subfamily members for FGFRs (Goetz et al. 2012a). For example, FGF21 primarily activates the FGFR1c- $\beta$ Klotho complex (Yie et al. 2012), whereas FGF19 is able to activate both FGFR1c- $\beta$ Klotho as well as FGFR4- $\beta$ Klotho. FGF23, on the other hand, binds promiscuously to FGFR1c $-\alpha$ Klotho, FGFR3c $-\alpha$ Klotho, and FGFR4- $\alpha$ Klotho (Yu et al. 2005; Goetz et al. 2012a).

Although the structural basis for ternary complex formation remains to be elucidated, biochemical studies have already provided significant insights into the molecular interactions between the components in the ternary complex (Fig. 4B). These studies have shown that the $\alpha$ Klotho and $\beta$ Klotho coreceptors employ two different mechanisms to promote ternary complex formation. $\alpha$ Klotho combines with FGFR1c to create a de novo site for the FGF23 carboxy tail, whereas $\beta$ Klotho uses two distinct sites to bind independently to the FGFR and to either the FGF19 or FGF21 carboxy tail (Wu et al. 2008; Goetz et al. 2012a). Consistent with the key role of the carboxy tail of FGF23 in signaling, the biological activity of FGF23 is downregulated by a naturally occurring proteolytic cleavage at an RXXR motif following the $\beta$-trefoil core (Shimada et al. 2001). Interestingly, the proteolytically cleaved carboxy tail can competitively inhibit binding of native FGF23 to the FGFR1c $-\alpha$ Klotho complex (Goetz et al. 2010, 2012a), indicating that this cleavage acts at two levels to inhibit FGF23 signaling: by inactivating FGF23 as well as by generating an endogenous inhibitor of FGF23 signaling. Pathogenic mutations of the RXXR motif abrogate proteolytic cleavage of the ligand (Shimada et al. 2002) and elevate the serum concentration of fulllength bioactive FGF23, which accelerates phosphate excretion in the kidney and results in autosomal dominant hypophosphatemic rickets (ADHR) (White et al. 2001). Recent biochemical data show that the mutation of residues that comprises the D3 hydrophobic groove in FGFRc isoforms and FGFR4, which mediates 
binding of the FGF8 subfamily, also abolishes Klotho binding (Goetz et al. 2012a). Consistent with the overlap between FGF8 and Klotho binding sites on FGFR, the association of the Klotho coreceptor with FGFRs retards the ability of these receptors to respond to FGF8, indicating that endocrine and paracrine FGF signaling impact each other.

The insights gained into the mechanism of endocrine FGF signaling are already being exploited to develop agonists and antagonists of the endocrine FGF system for treating metabolic diseases, including diabetes, obesity, and disorders associated with perturbed phosphate and bile acid homeostasis (Goetz et al. 2010). For example, a novel FGF21 agonist has been engineered by knocking out the HS binding affinity of FGF2 and swapping its carboxy-terminal tail with that ofFGF21 or FGF19 (Goetz et al. 2012b). This engineered FGF21 agonist is superior to native FGF21 in its insulin-sensitizing potential and is currently being evaluated in a mouse model for obesity. Using the same approach, FGF2 was converted into an FGF23 agonist, which may be used to treat patients with familial tumoral calcinosis, an inherited disorder, associated with loss-of-function mutations in FGF23 (Goetz et al. 2012b). Conversely, the carboxy-terminal tail of FGF23 is being developed for treatment of renal phosphate wasting disorders, and possibly for combating the cardiovascular morbidity factor in chronic kidney disease that has been shown to be caused by elevated FGF23 serum levels (Goetz et al. 2010).

\section{ALTERNATIVE SPLICING OF D1 AND D1-D2 LINKER CONTROLS RECEPTOR AUTOINHIBITION}

In FGFR1-3, a second major alternative splicing event (involving exons encoding D1 and the $\mathrm{AB}$-containing D1-D2 linker regions) generates receptor isoforms lacking D1, the D1-D2 linker, or both (Johnson et al. 1991; Givol and Yayon 1992; Hou et al. 1992; Xu et al. 1992; Shimizu et al. 2001). The loss of D1 and the D1-D2 linker enhances the affinity of FGFR for both HS and FGF, indicating that they play an autoinhibitory role in FGFR regulation (Wang et al. 1995; Roghani and Moscatelli 2007). The molecular basis by which these regions exert receptor autoinhibition has been interrogated using solution NMR and surface plasmon resonance (SPR) spectroscopies (Kalinina et al. 2012). The data show that the negatively charged AB subregion of the linker electrostatically engages the positively charged HS binding site on D2 in cis, thereby directly suppressing the HS affinity of the receptor (illustrated in Fig. 2A). Because of the close proximity of the HS binding site to the primary and secondary ligand-binding sites, as well as the direct receptor-receptor binding sites on $\mathrm{D} 2$, the cis electrostatic AB:HS interactions also sterically autoinhibits FGFFGFR binding and dimerization. Consistent with the $A B$ subregion playing a key role in FGFR autoinhibition, the amino acid sequence of the $\mathrm{AB}$ subregion is strongly conserved among FGFR orthologs (Kalinina et al. 2012).

\section{MECHANISM OF FGFR KINASE REGULATION}

HS or Klotho-dependent FGF-FGFR dimerization juxtaposes the cytoplasmic kinase domains, providing them with sufficient opportunity to trans-phosphorylate each other on specific tyrosine residues. A-loop tyrosine phosphorylation leads to a local rearrangement of the A loop into its active state, which in turn stabilizes the active conformation of the kinase globally and culminates in the upregulation of the intrinsic kinase activity (Hubbard 1999). Secondary phosphorylation events on tyrosines in the JM (juxtamembrane), kinase insert, and carboxy-tail regions are then ensued, providing docking sites for SH2-containing downstream signaling substrates, such as PLC $\gamma$ and CrkL (Eswarakumar et al. 2005; Seo et al. 2009). Crystallographic studies of FGFR kinases have afforded major insights into the molecular mechanisms of FGFR kinase regulation and deregulation in pathological states. The crystal structures of the FGFR1 kinase (FGFR1K) (Mohammadi et al. 1996; Bae et al. 2010) and FGFR2K (Chen et al. 2007) have been solved in both their unphosphorylated (low activity) and A-loop tyrosine phosphorylated (activated) states. Reminiscent of all cur- 
A.A. Belov and M. Mohammadi

rently solved A-loop phosphorylated RTK kinase domains, including IRK (Hubbard 1997), IGF1R (Favelyukis et al. 2001; Pautsch et al. 2001), and MUSK (Bergamin et al. 2010), the phosphate moiety of A-loop tyrosine (pY654 in FGFRK1 and pY657 in FGFRK2) engages in two hydrogen bonds with an RTK-invariant arginine in the first half of the A-loop (R646 in FGFR1 and R649 in FGFR2) to stabilize the active conformation of the A-loop (Chen et al. 2007; Bae et al. 2010) (Fig. 5C,D). This in turn triggers a more intimate interaction between the amino lobe and the carboxy lobe of kinase, optimally aligning residues from the A-loop, the catalytic loop, and the $\alpha \mathrm{C}$-helix to catalyze phosphotransfer reactions (Fig. 5D).

In sharp contrast to other unphosphorylated RTKs, in which the ATP and substrate binding pockets are occluded in cis by the kinase A-loop or JM region, these sites remain accessible in FGFRKs, although the conformation of the carboxyl-terminal end of the A-loop is not optimal for substrate binding (Mohammadi et al. 1996). A crystallographic analysis of FGFR2Ks harboring pathogenic gain-of-function mutations, responsible for craniosynostosis syndromes and cancers, has proved to be instrumental in unraveling the molecular mechanism

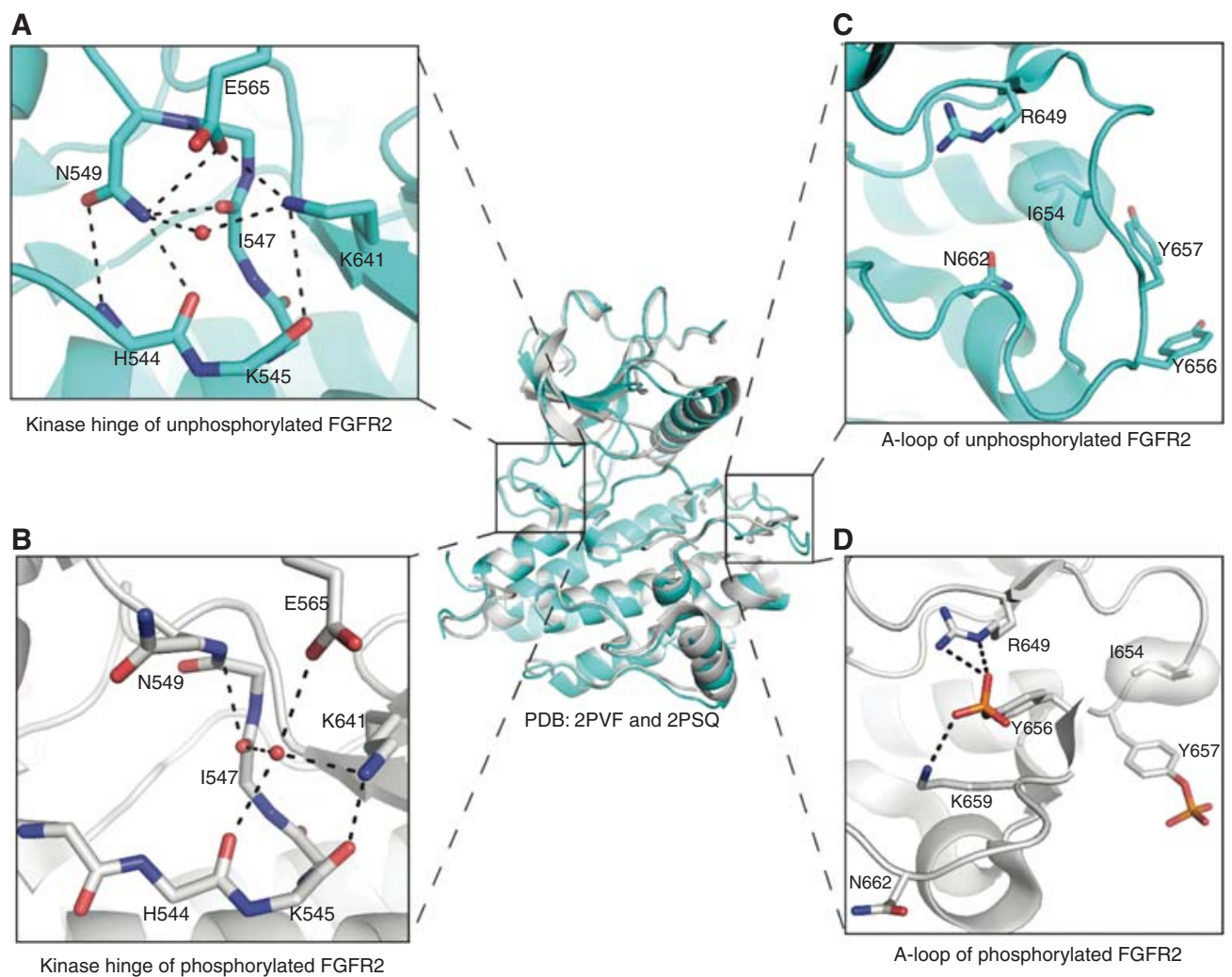

Figure 5. Comparison of FGFR2 kinases in the unphosphorylated and A-loop phosphorylated states. $(A)$ The inhibitory network of hydrogen bonds, termed the "molecular brake," at the kinase hinge/interlobe region of the unphosphorylated low-activity FGFR2 kinase (PDB: 2PSQ, cyan). (B) Disengagement of the molecular brake in the A-loop phosphorylated activated FGFR2 kinase (PDB: 2PVF, gray). (C) The unphosphorylated A-loop conformation and select amino acids are shown. $(D)$ The phosphorylated A-loop is held in an active conformation by hydrogen bonds between the phosphate moiety of phosphorylated A-loop tyrosine and basic residues (Arg-?? and Lys-??) within the A-loop. Note that on phosphorylation of A-loop Y656 and Y657, the A-loop undergoes a major conformational change as evidenced by the pistonlike conformational switch in the orientation of I654 and N662. 
of FGFRK autoinhibition (Chen et al. 2007). A comparison of these unphosphorylated "diseased" FGFR2Ks with the wild-type unphosphorylated and A-loop phosphorylated FGFRKs shows that kinase autoinhibition is controlled at the level of protein dynamics. Specifically, a network of hydrogen bonds mediated by a triad of residues from the kinase hinge (E565), the $\alpha \mathrm{C}-$ $\beta 4$ loop (N549), and the $\beta 8$ strand (K641), are engaged in an autoinhibitory network of hydrogen bonds (termed "molecular brake") at the kinase-hinge region that restricts the transition of the kinase into the active state, thus stabilizing the low activity state (Chen et al. 2007) (Fig. 5A,B). A-loop tyrosine phosphorylation or pathogenic gain-of-function mutations disengage this molecular break either directly or indirectly through allosteric communication between the A-loop and kinase hinge, thereby stabilizing the active state (Chen et al. 2007). The constituents of this molecular brake are conserved in other RTKs, including PDGFR, CSFLR, and KIT, and indicate that kinase regulation by a molecular brake may also apply to other RTKs.

Loss-of-function mutations in the tyrosine kinase domains of FGFRs are also implicated in human diseases, such as Kallmann syndrome, lacrimo-auriculo-dento-digital (LADD) syndrome, and cleft lip and palate. The crystal structure of FGFR2K, containing the A628T mutation responsible for LADD syndrome shows that the introduction of the polar and bulkier threonine sterically hinders formation of hydrogen bonds between Arg630 and Asp626 in the catalytic loop, thus hampering substrate tyrosine binding and phosphate-transfer reaction (Lew et al. 2007).

\section{STRUCTURAL BASIS FOR FGFR KINASE TRANS-AUTOPHOSPHORYLATION}

As introduced earlier, tyrosine trans-autophosphorylation fulfills two key roles in RTK signaling: (1) the upregulation of kinase activity, and (2) the generation of docking sites for downstream signaling proteins (Lemmon and Schlessinger 2010). Hence, elucidation of the structural basis for trans-phosphorylation is essential for grasping the mechanism of RTK signal transduction in physiological and pathological states and for identifying new strategies for targeted drug discovery. Two recent studies have captured snapshots ofFGFR1 and FGFR2 kinases caught in the act of trans-phosphorylation (Chen et al. 2008a; Bae et al. 2010). One kinase acts as the enzyme whereas the other kinase offers a phosphorylatable tyrosine from the kinase insert (Y583F in FGFR1) (Fig. 6B) or the carboxy-tail region (Y769 in FGFR2) (Chen et al. 2008a) (Fig. $6 \mathrm{~A})$. The structural data show that tyrosine transphosphorylation entails both a substantial degree of sequence specificity and structural complementarities. Both trans-phosphorylation complexes are asymmetric, whereby the carboxy lobe of the "substrate" engages both the amino lobe and carboxy lobe of the enzyme, burying a 1650 $\AA^{2}$ (kinase-insert tyrosine trans-phosphorylation complex) and a $1850 \AA^{2}$ (carboxy-tail tyrosine phosphorylation complex) solvent-exposed surface area. The enzyme-substrate interface can be roughly divided into a proximal (vicinity of the catalytic cleft) and a distal (remote from the catalytic cleft) site (Fig. 6A,B). At the proximal interface, the phosphorylatable tyrosine and its immediate surrounding sequences from the substrate engage the catalytic cleft of the enzyme, whereas in the distal interface, the carboxy-lobe regions of the substrate engage the amino lobe of the enzyme remote from the enzyme catalytic cleft.

The structural mode by which the enzyme and the substrate embrace each other is very different between these two trans-phosphorylation complexes. Importantly, the kinase-insert tyrosine and the carboxy-tail tyrosine of the substrate dock into the active site of the enzyme from the opposite direction (Fig. 6A,B). The overall topology of the carboxy-tail tyrosine trans-phosphorylation complex is dictated by the latching of the carboxyl-terminal end (negative pole) of the $\alpha \mathrm{I}$ helix of the substrate onto the amino-terminal end (positive pole) of the $\alpha G$ helix in the substrate at the proximal interface. This interaction assists Y769 (P-0) and its surrounding P-4 (T765) to $\mathrm{P}+3$ (L772) residues to optimally engage the active site and the $\mathrm{P}$ +1 pocket of the enzyme to mediate the proximal specificity. Prominent contacts at the prox- 
A.A. Belov and M. Mohammadi
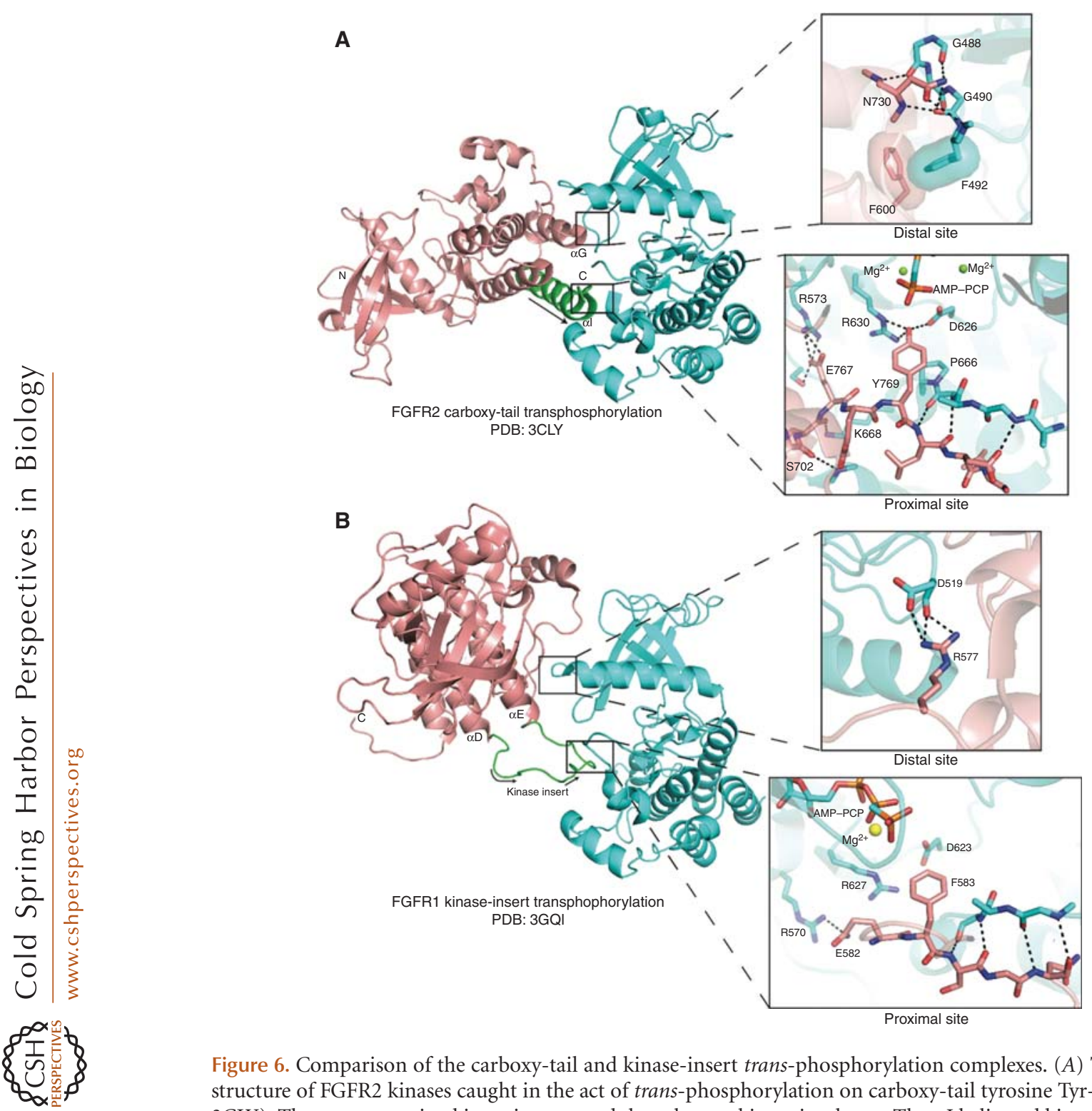

Figure 6. Comparison of the carboxy-tail and kinase-insert trans-phosphorylation complexes. $(A)$ The crystal structure of FGFR2 kinases caught in the act of trans-phosphorylation on carboxy-tail tyrosine Tyr-769 (PDB: 3CLY). The enzyme-acting kinase is cyan, and the substrate kinase is salmon. The $\alpha \mathrm{I}$ helix and kinase insert are green, with the amino to carboxy polarity indicated with arrows. $(B)$ The kinase-insert trans-phosphorylation complex (PDB: 3GQI) is colored as in A. Note that the kinase insert Tyr-583 has been mutated to phenylalanine. Compared to the carboxy-tail tyrosine trans-phosphorylation complex, there are fewer interactions between the enzyme and the substrate in the kinase-insert tyrosine trans-phosphorylation complex.

imal site include the salt bridge between E767 (P-2) of the substrate with R573 of the enzyme, hydrogen bonds of T765 (P-4) and N766 (P-3) with the $\alpha \mathrm{G}$ helix of the enzyme, and hydrophobic contacts of L770 $(\mathrm{P}+1)$ and $\mathrm{L} 772(\mathrm{P}+3)$ with a $\mathrm{P}+1$ pocket (Fig. 6 A, lower panel). Spe- cificity is augmented by specific contacts at the distal interface between the carboxy lobe of the substrate and the nucleotide-binding loop in the amino lobe of the enzyme. Prominent contacts at the distal site include perpendicular aromatic interactions between F600 of substrate 
and F492 of enzyme, and hydrogen bonds between N730 of substrate and backbone carbonyl oxygens of the nucleotide binding loop in the enzyme (Chen et al. 2008a).

In contrast, the enzyme-substrate relationship in the kinase-insert trans-phosphorylation complex is determined by contacts between the carboxy-lobe of substrate and the amino-lobe of enzyme at the distal site (Bae et al. 2010). Aside from the hydrogen bonds between R577 (from the amino-terminal end of the kinase insert) and backbone carbonyl oxygen atoms in the $\beta 3-$ $\alpha \mathrm{C}$ loop, all the remaining interactions at this distal contact site are of van der Waals nature. Interestingly, as in the carboxy-tail tyrosine trans-phosphorylation complex, the nucleotide binding loop of the enzyme partakes in the distal site, indicating that this loop, in addition to coordinating ATP, may also participate in substrate recognition. At the proximal site, the pseudosubstrate Phe583 (Tyr583) occupies a very similar position in the catalytic pocket of the enzyme-acting kinase, even though phenylalanine is not in position to form hydrogen bonds with the catalytic base D623 and R627 (Fig. 6B). Akin to the carboxy-tail tyrosine trans-phosphorylation complex, residues $\mathrm{P}-0$ to $\mathrm{P}+3$ form an antiparallel strand with $\beta 10$ in the Aloop. Compared to the carboxy-tail tyrosine trans-phosphorylation complex, there are significantly fewer interactions at the proximal site in the FGFR1 kinase-insert trans-phosphorylation complex. In fact the hydrophobic $\mathrm{P}+1$ pocket remains unengaged in this complex. Overall, the enzyme interface in the kinase-insert trans-phosphorylation complex contains fewer contacts and possesses lower shape complementarity than in the carboxy-tail tyrosine trans-phosphorylation complex (0.62 vs. 0.72$)$. These differences are consistent with the kinase autophosphorylation data showing that phosphorylation of carboxy-tail tyrosine precedes that of kinase-insert tyrosine (Furdui et al. 2006; Chen et al. 2008a).

\section{FUTURE PERSPECTIVES}

The structural studies have provided the molecular bases for several major signaling events in
FGF signaling, including FGF-FGFR specificity, HS-assisted FGF-FGFR dimerization, and FGFR kinase regulation. Many imminent questions in the FGF field remain for structural biologists to address, however. Elucidation of the crystal structure of the endocrine FGF-FGFRKlotho ternary complex is a top priority, as it will provide a novel mechanism by which FGFFGFR dimerization is achieved. Crystal structures with a representative from the FGF4 and FGF9 subfamilies in complex with their cognate FGFR should complete our understanding of the molecular mechanisms governing the specificity/promiscuity of this complex system. At the intracellular level, future work should be directed toward obtaining additional structures of trans-phosphorylation events, especially of the A-loop tyrosine phosphorylation, the gatekeeping phosphorylation event. Crystal structures of downstream signaling substrates in complex with the intracellular kinase domain will undoubtedly yield valuable information on how FGFR substrates are docked onto the kinase and are phosphorylated. The crystallographic data indicate that intrinsic protein dynamics may also modulate the activity of both the extracellular domain and intracellular domains of FGFRs (Chen et al. 2007; Kalinina et al. 2012). Ideally, the crystallographic snapshots should be complemented by NMR dynamic studies and computational methods to provide a more accurate four-dimensional perspective of FGF signaling. These structural data will be valuable in directing future biochemical interrogations of this complex signaling network, and provide a framework for a comprehensive understanding of the basis of disease and structure-based drug discovery for many human diseases where perturbed FGF signaling is implicated.

\section{ACKNOWLEDGMENTS}

We thank Yang Liu for critically reading the manuscript, and Jinghong Ma for assistance in figure preparation. This work is supported by the National Institute of Dental and Craniofacial Research Grant DE13686 (to M.M.). A.A.B. is partially supported by the Macromolecular 
A.A. Belov and M. Mohammadi

Structure and Mechanism Training Grant 5T32GM088118-03.

\section{REFERENCES}

Acland P, Dixon M, Peters G, Dickson C. 1990. Subcellular fate of the int-2 oncoprotein is determined by choice of initiation codon. Nature 343: 662-665.

Anderson J, Burns HD, Enriquez-Harris P, Wilkie AO, Heath JK. 1998. Apert syndrome mutations in fibroblast growth factor receptor 2 exhibit increased affinity for FGF ligand. Hum Mol Genet 7: 1475-1483.

Asada M, Shinomiya M, Suzuki M, Honda E, Sugimoto R, Ikekita M, Imamura T. 2009. Glycosaminoglycan affinity of the complete fibroblast growth factor family. Biochim Biophys Acta 1790: 40-48.

Bae JH, Boggon TJ, Tome F, Mandiyan V, Lax I, Schlessinger J. 2010. Asymmetric receptor contact is required for tyrosine autophosphorylation of fibroblast growth factor receptor in living cells. Proc Natl Acad Sci 107: 2866-2871.

Basilico C, Moscatelli D. 1992. The FGF family of growth factors and oncogenes. Adv Cancer Res 59: 115-165.

Bateman A, Chothia C. 1995. Outline structures for the extracellular domains of the fibroblast growth factor receptors. Nat Struct Biol 2: 1068-1074.

Beenken A, Mohammadi M. 2009. The FGF family: Biology, pathophysiology and therapy. Nat Rev Drug Discov 8: 235-253.

Beenken A, Mohammadi M. 2011. Craniosynostoses-Molecular genetics, principles of diagnosis, and treatment. Karger, Basel, Switzerland.

Beenken A, Mohammadi M. 2012. The structural biology of the FGF19 subfamily. Adv Exp Med Biol 728: 1-24.

Beenken A, Eliseenkova AV, Ibrahimi OA, Olsen SK, Mohammadi M. 2012. Plasticity in interactions of fibroblast growth factor 1 (FGF1) N terminus with FGF receptors underlies promiscuity of FGF1. J Biol Chem 287: 3067-3078.

Beer HD, Vindevoghel L, Gait MJ, Revest JM, Duan DR, Mason I, Dickson C, Werner S. 2000. Fibroblast growth factor (FGF) receptor 1-IIIb is a naturally occurring functional receptor for FGFs that is preferentially expressed in the skin and the brain. J Biol Chem 275: 16091-16097.

Bellosta P, Iwahori A, Plotnikov AN, Eliseenkova AV, Basilico C, Mohammadi M. 2001. Identification of receptor and heparin binding sites in fibroblast growth factor 4 by structure-based mutagenesis. Mol Cell Biol 21: 59465957.

Bergamin E, Hallock PT, Burden SJ, Hubbard SR. 2010. The cytoplasmic adaptor protein Dok7 activates the receptor tyrosine kinase MuSK via dimerization. Mol Cell 39: $100-109$.

Blunt AG, Lawshe A, Cunningham ML, Seto ML, Ornitz DM, MacArthur CA. 1997. Overlapping expression and redundant activation of mesenchymal fibroblast growth factor (FGF) receptors by alternatively spliced FGF-8 ligands. J Biol Chem 272: 3733-3738.

Chateau MT, Araiz C, Descamps S, Galas S. 2010. Klotho interferes with a novel FGF-signalling pathway and insu-
lin/Igf-like signalling to improve longevity and stress resistance in Caenorhabditis elegans. Aging (Albany NY) 2: 567-581.

Chen H, Ma J, Li W, Eliseenkova AV, Xu C, Neubert TA, Miller WT, Mohammadi M. 2007. A molecular brake in the kinase hinge region regulates the activity of receptor tyrosine kinases. Mol Cell 27: 717-730.

Chen H, Xu CF, Ma J, Eliseenkova AV, Li W, Pollock PM, Pitteloud N, Miller WT, Neubert TA, Mohammadi M. 2008a. A crystallographic snapshot of tyrosine transphosphorylation in action. Proc Natl Acad Sci 105: 19660-19665.

Chen WW, Li L, Yang GY, Li K, Qi XY, Zhu W, Tang Y, Liu H, Boden G. 2008b. Circulating FGF-21 levels in normal subjects and in newly diagnose patients with Type 2 diabetes mellitus. Exp Clin Endocrinol Diabetes 116: 65-68.

Colvin JS, White AC, Pratt SJ, Ornitz DM. 2001. Lung hypoplasia and neonatal death in Fgf9-null mice identify this gene as an essential regulator of lung mesenchyme. Development 128: 2095-2106.

Delehedde M, Seve M, Sergeant N, Wartelle I, Lyon M, Rudland PS, Fernig DG. 2000. Fibroblast growth factor2 stimulation of $\mathrm{p} 42 / 44 \mathrm{MAPK}$ phosphorylation and ІкB degradation is regulated by heparan sulfate/heparin in rat mammary fibroblasts. J Biol Chem 275: 33905-33910.

di Martino E, Tomlinson DC, Knowles MA. 2012. A decade of FGF receptor research in bladder cancer: Past, present, and future challenges. Adv Urol 2012: 429213.

Dionne CA, Crumley G, Bellot F, Kaplow JM, Searfoss G, Ruta M, Burgess WH, Jaye M, Schlessinger J. 1990. Cloning and expression of two distinct high-affinity receptors cross-reacting with acidic and basic fibroblast growth factors. EMBO J 9: 2685-2692.

Dionne CA, Jaye M, Schlessinger J. 1991. Structural diversity and binding of FGF receptors. Ann NY Acad Sci 638: 161-166.

Dode C, Levilliers J, Dupont JM, De Paepe A, Le Du N, Soussi-Yanicostas N, Coimbra RS, Delmaghani S, Compain-Nouaille S, Baverel F, et al. 2003. Loss-of-function mutations in FGFR1 cause autosomal dominant Kallmann syndrome. Nat Genet 33: 463-465.

Dubrulle J, Pourquie O. 2004. fgf8 mRNA decay establishes a gradient that couples axial elongation to patterning in the vertebrate embryo. Nature 427: 419-422.

Eriksson AE, Cousens LS, Weaver LH, Matthews BW. 1991. Three-dimensional structure of human basic fibroblast growth factor. Proc Natl Acad Sci 88: 3441-3445.

Esko JD, Lindahl U. 2001. Molecular diversity of heparan sulfate. J Clin Invest 108: 169-173.

Eswarakumar VP, Lax I, Schlessinger J. 2005. Cellular signaling by fibroblast growth factor receptors. Cytokine Growth Factor Rev 16: 139-149.

Faham S, Linhardt RJ, Rees DC. 1998. Diversity does make a difference: Fibroblast growth factor-heparin interactions. Curr Opin Struct Biol 8: 578-586.

Falardeau J, Chung WC, Beenken A, Raivio T, Plummer L, Sidis Y, Jacobson-Dickman EE, Eliseenkova AV, Ma J, Dwyer A, et al. 2008. Decreased FGF8 signaling causes deficiency of gonadotropin-releasing hormone in humans and mice. J Clin Invest 118: 2822-2831. 
Favelyukis S, Till JH, Hubbard SR, Miller WT. 2001. Structure and autoregulation of the insulin-like growth factor 1 receptor kinase. Nat Struct Biol 8: 1058-1063.

Feldman B, Poueymirou W, Papaioannou VE, DeChiara TM, Goldfarb M. 1995. Requirement of FGF-4 for postimplantation mouse development. Science 267: 246-249.

Finch PW, Rubin JS, Miki T, Ron D, Aaronson SA. 1989. Human KGF is FGF-related with properties of a paracrine effector of epithelial cell growth. Science 245: 752-755.

Fliser D, Kollerits B, Neyer U, Ankerst DP, Lhotta K, Lingenhel A, Ritz E, Kronenberg F, Kuen E, Konig P, et al. 2007. Fibroblast growth factor 23 (FGF23) predicts progression of chronic kidney disease: The mild to moderate kidney disease (MMKD) Study. J Am Soc Nephrol 18: 2600-2608.

Florkiewicz RZ, Sommer A. 1989. Human basic fibroblast growth factor gene encodes four polypeptides: Three initiate translation from non-AUG codons. Proc Natl Acad Sci 86: 3978-3981.

Fu L, John LM, Adams SH, Yu XX, Tomlinson E, Renz M, Williams PM, Soriano R, Corpuz R, Moffat B, et al. 2004. Fibroblast growth factor 19 increases metabolic rate and reverses dietary and leptin-deficient diabetes. Endocrinology 145: 2594-2603.

Furdui CM, Lew ED, Schlessinger J, Anderson KS. 2006. Autophosphorylation of FGFR1 kinase is mediated by a sequential and precisely ordered reaction. Mol Cell 21: 711-717.

Gartside MG, Chen H, Ibrahimi OA, Byron SA, Curtis AV, Wellens CL, Bengston A, Yudt LM, Eliseenkova AV, Ma J, et al. 2009. Loss-of-function fibroblast growth factor receptor-2 mutations in melanoma. Mol Cancer Res 7: $41-54$.

Gattineni J, Twombley K, Goetz R, Mohammadi M, Baum M. 2011. Regulation of serum $1,25(\mathrm{OH})_{2}$ vitamin D3 levels by fibroblast growth factor 23 is mediated by FGF receptors 3 and 4. Am J Physiol Renal Physiol 301: F371377.

Gemel J, Gorry M, Ehrlich GD, MacArthur CA. 1996. Structure and sequence of human FGF8. Genomics 35: 253257.

Givol D, Yayon A. 1992. Complexity of FGF receptors: Genetic basis for structural diversity and functional specificity. FASEB J 6: 3362-3369.

Glaser RL, Broman KW, Schulman RL, Eskenazi B, Wyrobek AJ, Jabs EW. 2003. The paternal-age effect in Apert syndrome is due, in part, to the increased frequency of mutations in sperm. Am J Hum Genet 73: 939-947.

Goetz R, Beenken A, Ibrahimi OA, Kalinina J, Olsen SK, Eliseenkova AV, Xu C, Neubert TA, Zhang F, Linhardt RJ, et al. 2007. Molecular insights into the klotho-dependent, endocrine mode of action of fibroblast growth factor 19 subfamily members. Mol Cell Biol 27: 3417-3428.

Goetz R, Dover K, Laezza F, Shtraizent N, Huang X, Tchetchik D, Eliseenkova AV, Xu CF, Neubert TA, Ornitz DM, et al. 2009. Crystal structure of a fibroblast growth factor homologous factor (FHF) defines a conserved surface on FHFs for binding and modulation of voltagegated sodium channels. J Biol Chem 284: 17883-17896.

Goetz R, Nakada Y, Hu MC, Kurosu H, Wang L, Nakatani T, Shi M, Eliseenkova AV, Razzaque MS, Moe OW, et al. 2010. Isolated C-terminal tail of FGF23 alleviates hypo- phosphatemia by inhibiting FGF23-FGFR-Klotho complex formation. Proc Natl Acad Sci 107: 407-412.

Goetz R, Ohnishi M, Ding X, Kurosu H, Wang L, Akiyoshi J, Ma J, Gai W, Sidis Y, Pitteloud N, et al. 2012a. Klotho coreceptors inhibit signaling by paracrine fibroblast growth factor 8 subfamily ligands. Mol Cell Biol 32: 1944-1954.

Goetz R, Ohnishi M, Kir S, Kurosu H, Wang L, Pastor J, Ma J, Gai W, Kuro OM, Razzaque MS, et al. 2012b. Conversion of a paracrine fibroblast growth factor into an endocrine fibroblast growth factor. J Biol Chem 287: 29134-29146.

Goldfarb M. 1996. Functions of fibroblast growth factors in vertebrate development. Cytokine Growth Factor Rev 7: 311-325.

Hacker U, Nybakken K, Perrimon N. 2005. Heparan sulphate proteoglycans: The sweet side of development. Nat Rev Mol Cell Biol 6: 530-541.

Harada M, Murakami H, Okawa A, Okimoto N, Hiraoka S, Nakahara T, Akasaka R, Shiraishi Y, Futatsugi N, Mizutani-Koseki Y, et al. 2009. FGF9 monomer-dimer equilibrium regulates extracellular matrix affinity and tissue diffusion. Nat Genet 41: 289-298.

Harmer NJ, Pellegrini L, Chirgadze D, Fernandez-Recio J, Blundell TL. 2004. The crystal structure of fibroblast growth factor (FGF) 19 reveals novel features of the FGF family and offers a structural basis for its unusual receptor affinity. Biochem 43: 629-640.

Holt JA, Luo G, Billin AN, Bisi J, McNeill YY, Kozarsky KF Donahee M, Wang DY, Mansfield TA, Kliewer SA, et al. 2003. Definition of a novel growth factor-dependent signal cascade for the suppression of bile acid biosynthesis. Genes Dev 17: 1581-1591

Hou J, Kan M, Wang F, Xu JM, Nakahara M, McBride G, McKeehan K, McKeehan WL. 1992. Substitution of putative half-cystine residues in heparin-binding fibroblast growth factor receptors. Loss of binding activity in both two and three loop isoforms. J Biol Chem 267: 1780417808 .

Huang Z, Wang H, Lu M, Sun C, Wu X, Tan Y, Ye C, Zhu G, Wang X, Cai L, et al. 2011. A better anti-diabetic recombinant human fibroblast growth factor 21 (rhFGF21) modified with polyethylene glycol. PLoS ONE 6: e20669.

Hubbard SR. 1997. Crystal structure of the activated insulin receptor tyrosine kinase in complex with peptide substrate and ATP analog. EMBO J 16: 5572-5581.

Hubbard SR. 1999. Structural analysis of receptor tyrosine kinases. Prog Biophys Mol Biol 71: 343-358.

Hung KW, Kumar TK, Kathir KM, Xu P, Ni F, Ji HH, Chen MC, Yang CC, Lin FP, Chiu IM, et al. 2005. Solution structure of the ligand binding domain of the fibroblast growth factor receptor: Role of heparin in the activation of the receptor. Biochem 44: 15787-15798.

Ibrahimi OA, Eliseenkova AV, Plotnikov AN, Yu K, Ornitz DM, Mohammadi M. 2001. Structural basis for fibroblast growth factor receptor 2 activation in Apert syndrome. Proc Natl Acad Sci 98: 7182-7187.

Ibrahimi OA, Zhang F, Eliseenkova AV, Itoh N, Linhardt RJ, Mohammadi M. 2004a. Biochemical analysis of pathogenic ligand-dependent FGFR2 mutations suggests distinct pathophysiological mechanisms for craniofacial and limb abnormalities. Hum Mol Genet 13: 2313-2324. 
Ibrahimi OA, Zhang F, Eliseenkova AV, Linhardt RJ, Mohammadi M. 2004b. Proline to arginine mutations in FGF receptors 1 and 3 result in Pfeiffer and Muenke craniosynostosis syndromes through enhancement of FGF binding affinity. Hum Mol Genet 13: 69-78.

Ibrahimi OA, Zhang F, Hrstka SC, Mohammadi M, Linhardt RJ. 2004c. Kinetic model for FGF, FGFR, and proteoglycan signal transduction complex assembly. Biochem 43: 4724-4730.

Ibrahimi OA, Chiu ES, McCarthy JG, Mohammadi M. 2005. Understanding the molecular basis of Apert syndrome. Plas Reconstr Surg 115: 264-270.

Imamura T, Mitsui Y. 1987. Heparan sulfate and heparin as a potentiator or a suppressor of growth of normal and transformed vascular endothelial cells. Exp Cell Res 172: 92-100.

Inagaki T, Dutchak P, Zhao G, Ding X, Gautron L, Parameswara V, Li Y, Goetz R, Mohammadi M, Esser V, et al. 2007. Endocrine regulation of the fasting response by PPAR $\alpha$-mediated induction of fibroblast growth factor 21. Cell Metab 5: 415-425.

Inatani M, Irie F, Plump AS, Tessier-Lavigne M, Yamaguchi Y. 2003. Mammalian brain morphogenesis and midline axon guidance require heparan sulfate. Science 302: 1044-1046.

Iozzo RV, Zoeller JJ, Nystrom A. 2009. Basement membrane proteoglycans: Modulators par excellence of cancer growth and angiogenesis. Mol Cell 27: 503-513.

Ito S, Kinoshita S, Shiraishi N, Nakagawa S, Sekine S, Fujimori T, Nabeshima YI. 2000. Molecular cloning and expression analyses of mouse $\beta$ klotho, which encodes a novel Klotho family protein. Mech Dev 98: 115-119.

Itoh N, Ornitz DM. 2011. Fibroblast growth factors: From molecular evolution to roles in development, metabolism and disease. J Biochem 149: 121-130.

Johnson DE, Williams LT. 1993. Structural and functional diversity in the FGF receptor multigene family. Adv Cancer Res 60: 1-41.

Johnson DE, Lee PL, Lu J, Williams LT. 1990. Diverse forms of a receptor for acidic and basic fibroblast growth factors. Mol Cell Biol 10: 4728-4736.

Johnson DE, Lu J, Chen H, Werner S, Williams LT. 1991. The human fibroblast growth factor receptor genes: A common structural arrangement underlies the mechanisms for generating receptor forms that differ in their third immunoglobulin domain. Mol Cell Biol 11: 4627-4634.

Kalinina J, Byron SA, Makarenkova HP, Olsen SK, Eliseenkova AV, Larochelle WJ, Dhanabal M, Blais S, Ornitz DM, Day LA, et al. 2009. Homodimerization controls the fibroblast growth factor 9 subfamily's receptor binding and heparan sulfate-dependent diffusion in the extracellular matrix. Mol Cell Biol 29: 4663-4678.

Kalinina J, Dutta K, Ilghari D, Beenken A, Goetz R, Eliseenkova AV, Cowburn D, Mohammadi M. 2012. The alternatively spliced acid box region plays a key role in FGF receptor autoinhibition. Structure 20: 77-88.

Kato S, Sekine K. 1999. FGF-FGFR signaling in vertebrate organogenesis. Cell Mol Biol (Noisy-le-grand) 45: 631638.

Kharitonenkov A, Dunbar JD, Bina HA, Bright S, Moyers JS, Zhang C, Ding L, Micanovic R, Mehrbod SF, Knier- man MD, et al. 2008. FGF-21/FGF-21 receptor interaction and activation is determined by $\beta$ Klotho. $J$ Cell Physiol 215: 1-7.

Kir S, Beddow SA, Samuel VT, Miller P, Previs SF, SuinoPowell K, Xu HE, Shulman GI, Kliewer SA, Mange1sdorf DJ. 2011. FGF19 as a postprandial, insulin-independent activator of hepatic protein and glycogen synthesis. Science 331: 1621-1624.

Kiselyov VV, Bock E, Berezin V, Poulsen FM. 2006. NMR structure of the first Ig module of mouse FGFR1. Protein Sci 15: 1512-1515.

Kuro-o M. 2012. Klotho and $\beta$ Klotho. Adv Exp Med Biol 728: $25-40$.

Kuro-o M, Matsumura Y, Aizawa H, Kawaguchi H, Suga T, Utsugi T, Ohyama Y, Kurabayashi M, Kaname T, Kume E, et al. 1997. Mutation of the mouse klotho gene leads to a syndrome resembling ageing. Nature 390: 45-51.

Kurosu H, Kuro-o M. 2008. The Klotho gene family and the endocrine fibroblast growth factors. Curr Opin Nephrol Hypertens 17: 368-372.

Kurosu H, Ogawa Y, Miyoshi M, Yamamoto M, Nandi A, Rosenblatt KP, Baum MG, Schiavi S, Hu MC, Moe OW, et al. 2006. Regulation of fibroblast growth factor- 23 signaling by klotho. J Biol Chem 281: 6120-6123.

Kurosu H, Choi M, Ogawa Y, Dickson AS, Goetz R, Eliseenkova AV, Mohammadi M, Rosenblatt KP, Kliewer SA, Kuro-o M. 2007. Tissue-specific expression of $\beta$ Klotho and fibroblast growth factor (FGF) receptor isoforms determines metabolic activity of FGF19 and FGF21. J Biol Chem 282: 26687-26695.

Lee PL, Johnson DE, Cousens LS, Fried VA, Williams LT. 1989. Purification and complementary DNA cloning of a receptor for basic fibroblast growth factor. Science 245: 57-60.

Lee HC, Tseng WA, Lo FY, Liu TM, Tsai HJ. 2009. FoxD5 mediates anterior-posterior polarity through upstream modulator Fgf signaling during zebrafish somitogenesis. Dev Biol 336: 232-245.

Lemmon MA, Schlessinger J. 2010. Cell signaling by receptor tyrosine kinases. Cell 141: 1117-1134.

Lew ED, Bae JH, Rohmann E, Wollnik B, Schlessinger J. 2007. Structural basis for reduced FGFR2 activity in LADD syndrome: Implications for FGFR autoinhibition and activation. Proc Natl Acad Sci 104: 19802-19807.

Lin X, Buff EM, Perrimon N, Michelson AM. 1999. Heparan sulfate proteoglycans are essential for FGF receptor signaling during Drosophila embryonic development. Development 126: $3715-3723$.

Luo Y, Lu W, Mohamedali KA, Jang JH, Jones RB, Gabriel JL, Kan M, McKeehan WL. 1998. The glycine box: A determinant of specificity for fibroblast growth factor. Biochem 37: 16506-16515.

Makarenkova HP, Hoffman MP, Beenken A, Eliseenkova AV, Meech R, Tsau C, Patel VN, Lang RA, Mohammadi M. 2009. Differential interactions of FGFs with heparan sulfate control gradient formation and branching morphogenesis. Sci Signal 2: ra55.

Mariani FV, Ahn CP, Martin GR. 2008. Genetic evidence that FGFs have an instructive role in limb proximal-distal patterning. Nature 453: 401-405. 
Martin GR. 1998. The roles of FGFs in the early development of vertebrate limbs. Genes Dev 12: 1571-1586.

Mason IJ, Fuller-Pace F, Smith R, Dickson C. 1994. FGF-7 (keratinocyte growth factor) expression during mouse development suggests roles in myogenesis, forebrain regionalisation and epithelial-mesenchymal interactions. Mech Dev 45: 15-30.

Mathieu M, Chatelain E, Ornitz D, Bresnick J, Mason I, Kiefer P, Dickson C. 1995. Receptor binding and mitogenic properties of mouse fibroblast growth factor 3 . Modulation of response by heparin. J Biol Chem 270: 24197-24203.

McCabe MJ, Gaston-Massuet C, Tziaferi V, Gregory LC, Alatzoglou KS, Signore M, Puelles E, Gerrelli D, Farooqi IS, Raza J, et al. 2011. Novel FGF8 mutations associated with recessive holoprosencephaly, craniofacial defects, and hypothalamo-pituitary dysfunction. J Clin Endocrinol Metab 96: E1709-E1718.

McEwen DG, Ornitz DM. 1997. Determination of fibroblast growth factor expression in mouse, rat and human samples using a single primer pair. Biotechniques 22: 1068 1070.

McIntosh I, Bellus GA, Jab EW. 2000. The pleiotropic effects of fibroblast growth factor receptors in mammalian development. Cell Struct Funct 25: 85-96.

Metzger RJ, Klein OD, Martin GR, Krasnow MA. 2008. The branching programme of mouse lung development. $\mathrm{Na}$ ture 453: 745-750.

Miki T, Bottaro DP, Fleming TP, Smith CL, Burgess WH, Chan AM, Aaronson SA. 1992. Determination of ligandbinding specificity by alternative splicing: Two distinct growth factor receptors encoded by a single gene. Proc Natl Acad Sci 89: 246-250.

Mohammadi M, Schlessinger J, Hubbard SR. 1996. Structure of the FGF receptor tyrosine kinase domain reveals a novel autoinhibitory mechanism. Cell 86: 577-587.

Mohammadi M, Olsen SK, Goetz R. 2005a. A protein canyon in the FGF-FGF receptor dimer selects from an a la carte menu of heparan sulfate motifs. Curr Opin Struct Biol 15: 506-516.

Mohammadi M, Olsen SK, Ibrahimi OA. 2005b. Structural basis for fibroblast growth factor receptor activation. $C y$ tokine Growth Factor Rev 16: 107-137.

Moyers JS, Shiyanova TL, Mehrbod F, Dunbar JD, Noblitt TW, Otto KA, Reifel-Miller A, Kharitonenkov A. 2007. Molecular determinants of FGF-21 activity-synergy and cross-talk with PPAR $\gamma$ signaling. J Cell Physiol 210: $1-6$.

Naiche LA, Holder N, Lewandoski M. 2011. FGF4 and FGF8 comprise the wavefront activity that controls somitogenesis. Proc Natl Acad Sci 108: 4018-4023.

Nakatani T, Sarraj B, Ohnishi M, Densmore MJ, Taguchi T, Goetz R, Mohammadi M, Lanske B, Razzaque MS. 2009. In vivo genetic evidence for klotho-dependent, fibroblast growth factor 23 (Fgf23) -mediated regulation of systemic phosphate homeostasis. FASEB J 23: 433-441.

Naski MC, Wang Q, Xu J, Ornitz DM. 1996. Graded activation of fibroblast growth factor receptor 3 by mutations causing achondroplasia and thanatophoric dysplasia. Nat Genet 13: 233-237.
Niwa Y, Shimojo H, Isomura A, Gonzalez A, Miyachi H, Kageyama R. 2011. Different types of oscillations in Notch and Fgf signaling regulate the spatiotemporal periodicity of somitogenesis. Genes Dev 25: 1115-1120.

Nugent MA, Edelman ER. 1992. Kinetics of basic fibroblast growth factor binding to its receptor and heparan sulfate proteoglycan: A mechanism for cooperactivity. Biochem 31: 8876-8883.

Ogawa Y, Kurosu H, Yamamoto M, Nandi A, Rosenblatt KP, Goetz R, Eliseenkova AV, Mohammadi M, Kuro-o M. 2007. $\beta$ Klotho is required for metabolic activity of fibroblast growth factor 21. Proc Natl Acad Sci 104: $7432-7437$.

Olsen SK, Garbi M, Zampieri N, Eliseenkova AV, Ornitz DM, Goldfarb M, Mohammadi M. 2003. Fibroblast growth factor (FGF) homologous factors share structural but not functional homology with FGFs. J Biol Chem 278: 34226-34236.

Olsen SK, Ibrahimi OA, Raucci A, Zhang F, Eliseenkova AV, Yayon A, Basilico C, Linhardt RJ, Schlessinger J, Mohammadi M. 2004. Insights into the molecular basis for fibroblast growth factor receptor autoinhibition and ligand-binding promiscuity. Proc Natl Acad Sci 101: 935-940.

Olsen SK, Li JY, Bromleigh C, Eliseenkova AV, Ibrahimi OA, Lao Z, Zhang F, Linhardt RJ, Joyner AL, Mohammadi M. 2006. Structural basis by which alternative splicing modulates the organizer activity of FGF8 in the brain. Genes Dev 20: 185-198.

Olwin BB, Rapraeger A. 1992. Repression of myogenic differentiation by aFGF, bFGF, and K-FGF is dependent on cellular heparan sulfate. J Cell Biol 118: 631-639.

Ornitz DM, Itoh N. 2001. Fibroblast growth factors. Genome Biol 2: REVIEWS3005.

Ornitz DM, Leder P. 1992. Ligand specificity and heparin dependence of fibroblast growth factor receptors 1 and 3 . J Biol Chem 267: 16305-16311.

Ornitz DM, Yayon A, Flanagan JG, Svahn CM, Levi E, Leder P. 1992. Heparin is required for cell-free binding of basic fibroblast growth factor to a soluble receptor and for mitogenesis in whole cells. Mol Cell Biol 12: 240-247.

Ornitz DM, Xu J, Colvin JS, McEwen DG, MacArthur CA Coulier F, Gao G, Goldfarb M. 1996. Receptor specificity of the fibroblast growth factor family. J Biol Chem 271: 15292-15297.

Orr-Urtreger A, Bedford MT, Burakova T, Arman E, Zimmer Y, Yayon A, Givol D, Lonai P. 1993. Developmental localization of the splicing alternatives of fibroblast growth factor receptor-2 (FGFR2). Dev Biol 158: 475486.

Pautsch A, Zoephel A, Ahorn H, Spevak W, Hauptmann R, Nar H. 2001. Crystal structure of bisphosphorylated IGF-1 receptor kinase: Insight into domain movements upon kinase activation. Structure 9: 955-965.

Pellegrini L, Burke DF, von Delft F, Mulloy B, Blundell TL. 2000. Crystal structure of fibroblast growth factor receptor ectodomain bound to ligand and heparin. Nature 407: 1029-1034.

Pitteloud N, Acierno JS Jr, Meysing A, Eliseenkova AV, Ma J, Ibrahimi OA, Metzger DL, Hayes FJ, Dwyer AA, Hughes VA, et al. 2006a. Mutations in fibroblast growth factor receptor 1 cause both Kallmann syndrome and 
normosmic idiopathic hypogonadotropic hypogonadism. Proc Natl Acad Sci 103: 6281-6286.

Pitteloud N, Meysing A, Quinton R, Acierno JS Jr, Dwyer AA, Plummer L, Fliers E, Boepple P, Hayes F, Seminara S, et al. 2006b. Mutations in fibroblast growth factor receptor 1 cause Kallmann syndrome with a wide spectrum of reproductive phenotypes. Mol Cell Endocrinol 254-255: 60-69.

Plotnikov AN, Schlessinger J, Hubbard SR, Mohammadi M 1999. Structural basis for FGF receptor dimerization and activation. Cell 98: 641-650.

Plotnikov AN, Hubbard SR, Schlessinger J, Mohammadi M 2000. Crystal structures of two FGF-FGFR complexes reveal the determinants of ligand-receptor specificity. Cell 101: 413-424.

Plotnikov AN, Eliseenkova AV, Ibrahimi OA, Shriver Z, Sasisekharan R, Lemmon MA, Mohammadi M. 2001. Crystal structure of fibroblast growth factor 9 reveals regions implicated in dimerization and autoinhibition. J Biol Chem 276: 4322-4329.

Pollock PM, Gartside MG, Dejeza LC, Powell MA, Mallon MA, Davies H, Mohammadi M, Futreal PA, Stratton MR, Trent JM, et al. 2007. Frequent activating FGFR2 mutations in endometrial carcinomas parallel germline mutations associated with craniosynostosis and skeletal dysplasia syndromes. Oncogene 26: 7158- 7162.

Popovici C, Roubin R, Coulier F, Birnbaum D. 2005. An evolutionary history of the FGF superfamily. BioEssays 27: 849-857.

Powell AK, Fernig DG, Turnbull JE. 2002. Fibroblast growth factor receptors 1 and 2 interact differently with heparin/ heparan sulfate. Implications for dynamic assembly of a ternary signaling complex. J Biol Chem 277: 2855428563.

Prats H, Kaghad M, Prats AC, Klagsbrun M, Lelias JM, Liauzun P, Chalon P, Tauber JP, Amalric F, Smith JA, et al. 1989. High molecular mass forms of basic fibroblast growth factor are initiated by alternative CUG codons. Proc Natl Acad Sci 86: 1836-1840.

Rand V, Huang J, Stockwell T, Ferriera S, Buzko O, Levy S, Busam D, Li K, Edwards JB, Eberhart C, et al. 2005. Sequence survey of receptor tyrosine kinases reveals mutations in glioblastomas. Proc Natl Acad Sci 102: 1434414349.

Rapraeger AC, Krufka A, Olwin BB. 1991. Requirement of heparan sulfate for bFGF-mediated fibroblast growth and myoblast differentiation. Science 252: 1705-1708.

Razzaque MS, Lanske B. 2007. The emerging role of the fibroblast growth factor-23-klotho axis in renal regulation of phosphate homeostasis. J Endocrinol 194: 1-10.

Reinehr T, Woelfle J, Wunsch R, Roth CL. 2012. Fibroblast growth factor 21 (FGF-21) and its relation to obesity, metabolic syndrome, and nonalcoholic fatty liver in children: A longitudinal analysis. J Clin Endocrinol Metab 97: 2143-2150.

Rodriguez Esteban C, Capdevila J, Economides AN, Pascual J, Ortiz A, Izpisua Belmonte JC. 1999. The novel Cer-like protein Caronte mediates the establishment of embryonic left-right asymmetry. Nature 401: 243-251.

Roghani M, Moscatelli D. 2007. Prostate cells express two isoforms of fibroblast growth factor receptor 1 with dif- ferent affinities for fibroblast growth factor-2. Prostate 67: $115-124$.

Schlessinger J, Plotnikov AN, Ibrahimi OA, Eliseenkova AV, Yeh BK, Yayon A, Linhardt RJ, Mohammadi M. 2000. Crystal structure of a ternary FGF-FGFR-heparin complex reveals a dual role for heparin in FGFR binding and dimerization. Mol Cell 6: 743-750.

Sekine K, Ohuchi H, Fujiwara M, Yamasaki M, Yoshizawa T, Sato T, Yagishita N, Matsui D, Koga Y, Itoh N, et al. 1999. Fgf10 is essential for limb and lung formation. Nat Genet 21: $138-141$.

Seo JH, Suenaga A, Hatakeyama M, Taiji M, Imamoto A. 2009. Structural and functional basis of a role for CRKL in a fibroblast growth factor 8 -induced feed-forward loop. Mol Cell Biol 29: 3076-3087.

Serls AE, Doherty S, Parvatiyar P, Wells JM, Deutsch GH. 2005. Different thresholds of fibroblast growth factors pattern the ventral foregut into liver and lung. Development 132: 35-47.

Shimada T, Mizutani S, Muto T, Yoneya T, Hino R, Takeda S, Takeuchi Y, Fujita T, Fukumoto S, Yamashita T. 2001. Cloning and characterization of FGF23 as a causative factor of tumor-induced osteomalacia. Proc Natl Acad Sci 98: 6500-6505.

Shimada T, Muto T, Urakawa I, Yoneya T, Yamazaki Y, Okawa K, Takeuchi Y, Fujita T, Fukumoto S, Yamashita T. 2002. Mutant FGF-23 responsible for autosomal dominant hypophosphatemic rickets is resistant to proteolytic cleavage and causes hypophosphatemia in vivo. Endocrinology 143: 3179-3182.

Shimizu A, Tada K, Shukunami C, Hiraki Y, Kurokawa T, Magane N, Kurokawa-Seo M. 2001. A novel alternatively spliced fibroblast growth factor receptor 3 isoform lacking the acid box domain is expressed during chondrogenic differentiation of ATDC5 cells. J Biol Chem 276: 11031-11040.

Stauber DJ, DiGabriele AD, Hendrickson WA. 2000. Structural interactions of fibroblast growth factor receptor with its ligands. Proc Natl Acad Sci 97: 49-54.

Sun X, Meyers EN, Lewandoski M, Martin GR. 1999. Targeted disruption of Fgf8 causes failure of cell migration in the gastrulating mouse embryo. Genes Dev 13: 18341846.

Suzuki M, Uehara Y, Motomura-Matsuzaka K, Oki J, Koyama Y, Kimura M, Asada M, Komi-Kuramochi A, Oka S, Imamura T. 2008. $\beta$ Klotho is required for fibroblast growth factor (FGF) 21 signaling through FGF receptor (FGFR) 1c and FGFR3c. Mol Endocrinol 22: 1006-1014.

Tanaka Y, Okada Y, Hirokawa N. 2005. FGF-induced vesicular release of Sonic hedgehog and retinoic acid in leftward nodal flow is critical for left-right determination. Nature 435: 172-177.

Tekin M, Hismi BO, Fitoz S, Ozdag H, Cengiz FB, Sirmaci A, Aslan I, Inceoglu B, Yuksel-Konuk EB, Yilmaz ST, et al. 2007. Homozygous mutations in fibroblast growth factor 3 are associated with a new form of syndromic deafness characterized by inner ear agenesis, microtia, and microdontia. Am J Hum Genet 80: 338-344.

Tekin M, Ozturkmen Akay H, Fitoz S, Birnbaum S, Cengiz FB, Sennaroglu L, Incesulu A, Yuksel Konuk EB, Hasanefendioglu Bayrak A, Senturk S, et al. 2008. Homozygous FGF3 mutations result in congenital deafness with 
inner ear agenesis, microtia, and microdontia. Clin Genet 73: 554-565.

Trarbach EB, Abreu AP, Silveira LF, Garmes HM, Baptista MT, Teles MG, Costa EM, Mohammadi M, Pitteloud N, Mendonca BB, et al. 2010. Nonsense mutations in FGF8 gene causing different degrees of human gonadotropin-releasing deficiency. J Clin Endocrinol Metab 95: 3491-3496.

Trueb B. 2011. Biology of FGFRL1, the fifth fibroblast growth factor receptor. Cell Mol Life Sci 68: 951-964.

Urakawa I, Yamazaki Y, Shimada T, Iijima K, Hasegawa H, Okawa K, Fujita T, Fukumoto S, Yamashita T. 2006. Klotho converts canonical FGF receptor into a specific receptor for FGF23. Nature 444: 770-774.

Vega-Hernandez M, Kovacs A, De Langhe S, Ornitz DM. 2011. FGF10/FGFR2b signaling is essential for cardiac fibroblast development and growth of the myocardium. Development 138: 3331-3340.

Wahl MB, Deng C, Lewandoski M, Pourquie O. 2007. FGF signaling acts upstream of the NOTCH and WNT signaling pathways to control segmentation clock oscillations in mouse somitogenesis. Development 134: 4033-4041.

Wang F, Kan M, Yan G, Xu J, McKeehan WL. 1995. Alternately spliced NH2-terminal immunoglobulin-like Loop I in the ectodomain of the fibroblast growth factor (FGF) receptor 1 lowers affinity for both heparin and FGF-1. J Biol Chem 270: 10231-10235.

Wang C, Chung BC, Yan H, Lee SY, Pitt GS. 2012. Crystal structure of the ternary complex of a NaV C-terminal domain, a fibroblast growth factor homologous factor, and calmodulin. Structure 20: 1167-1176.

White KE, Evans WE, O'Riordan JLH, Speer MC, Econs MJ, Lorenz-Depiereux B, Grabowski M, Meitinger T, Strom TM. 2000. Autosomal dominant hypophosphataemic rickets is associated with mutations in FGF23. Nat Genet 26: 345-348.

White KE, Carn G, Lorenz-Depiereux B, Benet-Pages A, Strom TM, Econs MJ. 2001. Autosomal-dominant hypophosphatemic rickets (ADHR) mutations stabilize FGF23. Kidney Int 60: 2079-2086.

Wilkie AO. 2005. Bad bones, absent smell, selfish testes: The pleiotropic consequences of human FGF receptor mutations. Cytokine Growth Factor Rev 16: 187-203.

Wilkie AO, Slaney SF, Oldridge M, Poole MD, Ashworth GJ, Hockley AD, Hayward RD, David DJ, Pulleyn LJ, Rutland P, et al. 1995. Apert syndrome results from localized mutations of FGFR2 and is allelic with Crouzon syndrome. Nat Genet 9: 165-172.

Wilkie AO, Patey SJ, Kan SH, van den Ouweland AM, Hamel BC. 2002. FGFs, their receptors, and human limb malformations: clinical and molecular correlations. Am J Med Genet 112: 266-278.

Wu X, Ge H, Gupte J, Weiszmann J, Shimamoto G, Stevens J, Hawkins N, Lemon B, Shen W, Xu J, et al. 2007. Coreceptor requirements for fibroblast growth factor-19 signaling. J Biol Chem 282: 29069-29072.

Wu X, Lemon B, Li X, Gupte J, Weiszmann J, Stevens J, Hawkins N, Shen W, Lindberg R, Chen JL, et al. 2008. C-terminal tail of FGF19 determines its specificity toward Klotho co-receptors. J Biol Chem 283: 3330433309.
Wuechner C, Nordqvist AC, Winterpacht A, Zabel B, Schalling M. 1996. Developmental expression of splicing variants of fibroblast growth factor receptor 3 (FGFR3) in mouse. Int J Dev Biol 40: 1185-1188.

Xu J, Nakahara M, Crabb JW, Shi E, Matuo Y, Fraser M, Kan M, Hou J, McKeehan WL. 1992. Expression and immunochemical analysis of rat and human fibroblast growth factor receptor (flg) isoforms. J Biol Chem 267: $17792-17803$.

Xu J, Lawshe A, MacArthur CA, Ornitz DM. 1999. Genomic structure, mapping, activity and expression of fibroblast growth factor 17. Mech Dev 83: 165-178.

Xu R, Ori A, Rudd TR, Uniewicz KA, Ahmed YA, Guimond SE, Skidmore MA, Siligardi G, Yates EA, Fernig DG. 2012. Diversification of the structural determinants of fibroblast growth factor-heparin interactions: Implications for binding specificity. J Biol Chem.

Yayon A, Klagsbrun M, Esko JD, Leder P, Ornitz DM. 1991. Cell surface, heparin-like molecules are required for binding of basic fibroblast growth factor to its high affinity receptor. Cell 64: 841-848.

Yayon A, Zimmer Y, Shen GH, Avivi A, Yarden Y, Givol D. 1992. A confined variable region confers ligand specificity on fibroblast growth factor receptors: Implications for the origin of the immunoglobulin fold. EMBO J 11: 1885 1890.

Ye S, Luo Y, Lu W, Jones RB, Linhardt RJ, Capila I, Toida T, Kan M, Pelletier H, McKeehan WL. 2001. Structural basis for interaction of FGF-1, FGF-2, and FGF-7 with different heparan sulfate motifs. Biochem 40: 14429-14439.

Yeh BK, Igarashi M, Eliseenkova AV, Plotnikov AN, Sher I, Ron D, Aaronson SA, Mohammadi M. 2003. Structural basis by which alternative splicing confers specificity in fibroblast growth factor receptors. Proc Natl Acad Sci 100: 2266-2271.

Yie J, Wang W, Deng L, Tam LT, Stevens J, Chen MM, Li Y, Xu J, Lindberg R, Hecht R, et al. 2012. Understanding the physical interactions in the FGF21/FGFR/ $\beta$-Klotho complex: Structural requirements and implications in FGF21 signaling. Chem Biol Drug Des 79: 398-410.

Yoon SR, Qin J, Glaser RL, Jabs EW, Wexler NS, Sokol R, Arnheim N, Calabrese P. 2009. The ups and downs of mutation frequencies during aging can account for the Apert syndrome paternal age effect. PLoS Genet 5: e1000558.

Yu K, Ornitz DM. 2001. Uncoupling fibroblast growth factor receptor 2 ligand binding specificity leads to Apert syndrome-like phenotypes. Proc Natl Acad Sci 98: 36413643.

Yu C, Wang F, Kan M, Jin C, Jones RB, Weinstein M, Deng CX, McKeehan WL. 2000a. Elevated cholesterol metabolism and bile acid synthesis in mice lacking membrane tyrosine kinase receptor FGFR4. J Biol Chem 275: $15482-15489$.

Yu K, Herr AB, Waksman G, Ornitz DM. 2000b. Loss of fibroblast growth factor receptor 2 ligand-binding specificity in Apert syndrome. Proc Natl Acad Sci 97: 1453614541.

Yu X, Ibrahimi OA, Goetz R, Zhang F, Davis SI, Garringer HJ, Linhardt RJ, Ornitz DM, Mohammadi M, White KE. 2005. Analysis of the biochemical mechanisms for the endocrine actions of fibroblast growth factor-23. Endocrinology 146: 4647-4656. 
A.A. Belov and M. Mohammadi

Zhang JD, Cousens LS, Barr PJ, Sprang SR. 1991. Threedimensional structure of human basic fibroblast growth factor, a structural homolog of interleukin $1 \beta$. Proc Natl Acad Sci 88: 3446-3450.

Zhang X, Ibrahimi OA, Olsen SK, Umemori H, Mohammadi M, Ornitz DM. 2006. Receptor specificity of the fibroblast growth factor family. The complete mammalian FGF family. J Biol Chem 281: 15694-15700.
Zhang F, Zhang Z, Lin X, Beenken A, Eliseenkova AV, Mohammadi M, Linhardt RJ. 2009. Compositional analysis on heparin/heparan sulfate interacting with FGF•FGFR complexes. Biochemistry 48: 8379-8386.

Zhu X, Komiya H, Chirino A, Faham S, Fox GM, Arakawa T, Hsu BT, Rees DC. 1991. Three-dimensional structures of acidic and basic fibroblast growth factors. Science 251: 90-93. 


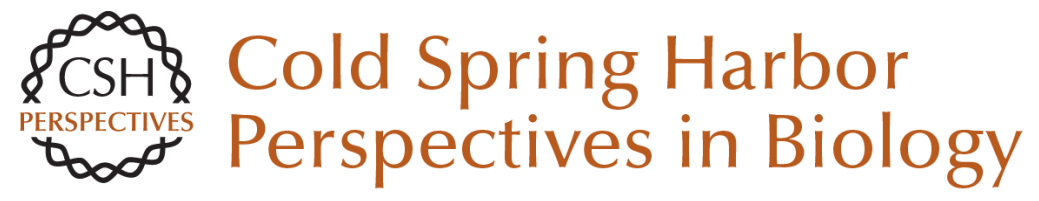

\section{Molecular Mechanisms of Fibroblast Growth Factor Signaling in Physiology and Pathology}

Artur A. Belov and Moosa Mohammadi

Cold Spring Harb Perspect Biol 2013; doi: 10.1101/cshperspect.a015958

Subject Collection Signaling by Receptor Tyrosine Kinases

CSF-1 Receptor Signaling in Myeloid Cells

E. Richard Stanley and Violeta Chitu

The EGFR Family: Not So Prototypical Receptor

Tyrosine Kinases

Mark A. Lemmon, Joseph Schlessinger and

Kathryn M. Ferguson

Tie2 and Eph Receptor Tyrosine Kinase Activation and Signaling

William A. Barton, Annamarie C. Dalton, Tom C.M. Seegar, et al.

The Spatiotemporal Organization of ErbB Receptors: Insights from Microscopy

Christopher C. Valley, Keith A. Lidke and Diane S. Lidke

Insulin Receptor Signaling in Normal and Insulin-Resistant States

Jérémie Boucher, André Kleinridders and C. Ronald Kahn

Central Role of RET in Thyroid Cancer Massimo Santoro and Francesca Carlomagno

Receptor Tyrosine Kinase-Mediated Angiogenesis Michael Jeltsch, Veli-Matti Leppänen, Pipsa Saharinen, et al.
The Genesis of Tyrosine Phosphorylation Tony Hunter

Structure-Function Relationships of ErbB RTKs in the Plasma Membrane of Living Cells Donna J. Arndt-Jovin, Michelle G. Botelho and Thomas M. Jovin

Receptor Tyrosine Kinases: Legacy of the First Two Decades Joseph Schlessinger

The Role of Ryk and Ror Receptor Tyrosine Kinases in Wnt Signal Transduction Jennifer Green, Roel Nusse and Renée van Amerongen

Regulation of Receptor Tyrosine Kinase Ligand Processing Colin Adrain and Matthew Freeman

Molecular Mechanisms of SH2- and PTB-Domain-Containing Proteins in Receptor Tyrosine Kinase Signaling Melany J. Wagner, Melissa M. Stacey, Bernard A. Liu, et al.

Eph Receptor Signaling and Ephrins Erika M. Lisabeth, Giulia Falivelli and Elena B. Pasquale

For additional articles in this collection, see http://cshperspectives.cshlp.org/cgi/collection/

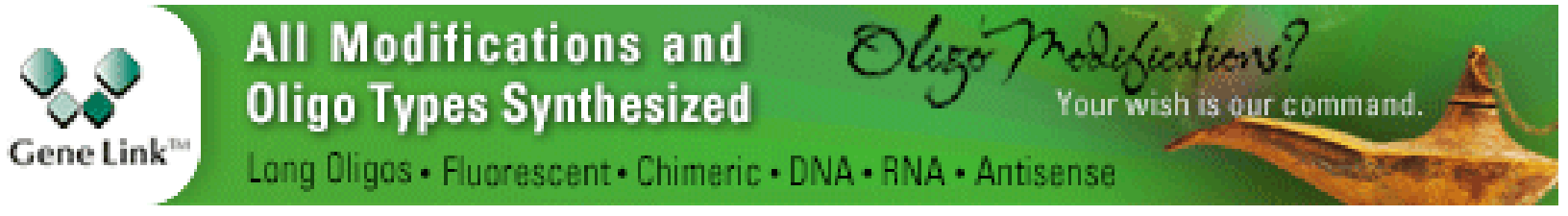




\section{Biology of the TAM Receptors \\ Greg Lemke}

Effects of Membrane Trafficking on Signaling by

Receptor Tyrosine Kinases

Marta Miaczynska

For additional articles in this collection, see http://cshperspectives.cshlp.org/cgi/collection/

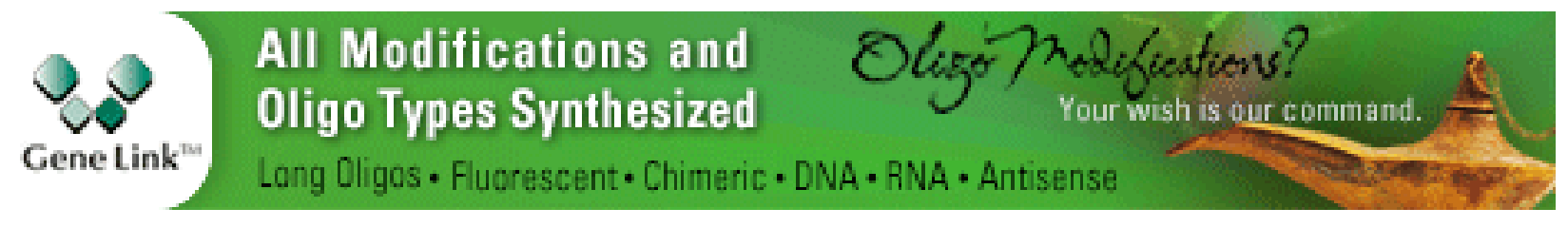

Copyright @ 2013 Cold Spring Harbor Laboratory Press; all rights reserved 